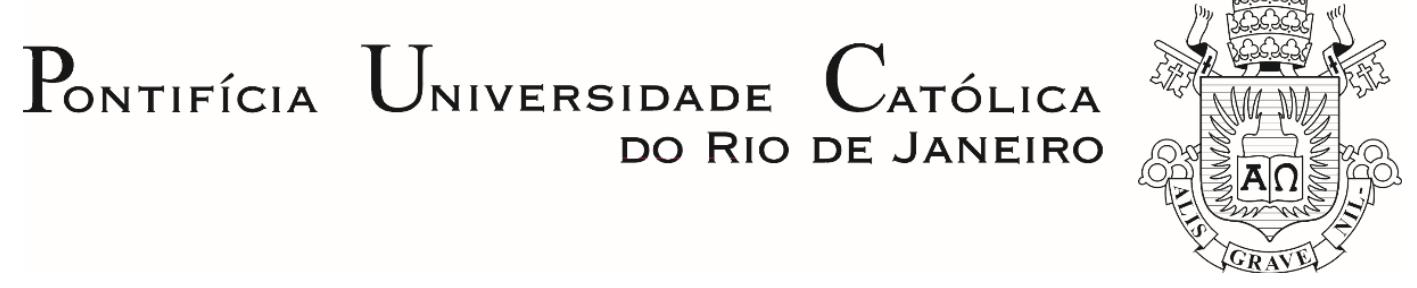

Rafael da Silva Fernandes

\begin{abstract}
Extensão do tempo de ciclo para tempo de jornada: Inclusão do tempo de pátio e aplicação a uma indústria de varejo
\end{abstract}

Dissertação de Mestrado

Dissertação apresentada ao Programa de Pós-graduação em Engenharia Industrial da PUC-Rio como requisito parcial para obtenção do grau de Mestre em Engenharia de Produção.

Orientador: Prof. Hugo Miguel Varela Repolho

Rio de Janeiro

Julho de 2017 
Rafael da Silva Fernandes

\title{
Extensão do tempo de ciclo para tempo de jornada: Inclusão do tempo de pátio e aplicação a uma indústria de varejo.
}

\begin{abstract}
Dissertação apresentada como requisito parcial para obtenção do grau de Mestre (opção profissional) pelo Programa de Pós-Graduação em Engenharia de Produção da PUC-Rio. Aprovada pela Comissão Examinadora abaixo assinada.
\end{abstract}

Prof. Hugo Miguel Varela Repolho

Orientador

Departamento de Engenharia Industrial - PUC-Rio

Prof. Fernando Luiz Cyrino Oliveira Departamento de Engenharia Industrial - PUC-Rio

Prof. José Eugenio Leal Departamento de Engenharia Industrial - PUC-Rio

Prof. Márcio da Silveira Carvalho Coordenador (a) Setorial do Centro Técnico Científico - PUC-Rio

Rio de Janeiro, 10 de julho de 2017. 
Todos os direitos reservados. É proibida a reprodução total ou parcial do trabalho sem autorização da universidade, do autor e do orientador.

\section{Rafael da Silva Fernandes}

Graduou-se em Ciência da Computação pela Universidade da Cidade de São Paulo, em 2004. Atua na área de Gestão e Transporte e Distribuição desde 2002. Dentre as principais atividades desenvolvidas estão projetos relacionados a implementação de melhoria no processo de distribuição e gestão de transporte.

Ficha catalográfica

\section{Fernandes, Rafael da Silva}

Extensão do tempo de ciclo para tempo de jornada: Inclusão do tempo de pátio e aplicação a uma indústria de varejo / Rafael da Silva Fernandes; orientador: Hugo Miguel Varela Repolho- Rio de Janeiro: Pontifícia Universidade Católica do Rio de Janeiro, Departamento de Engenharia Industrial, 2017.

$$
\text { v. } 77 \mathrm{f.:} \mathrm{il;} 29,7 \mathrm{~cm}
$$

Dissertação (mestrado) - Pontifícia Universidade Católica do Rio de Janeiro, Departamento de Engenharia Industrial, 2017.

\section{Inclui bibliografia}

1. Engenharia Industrial - Teses. 2. Roteirização. 3. Tempo de ciclo. 4. Teoria de Filas. 5. Mapa de fluxo de valor. 6. Simulação. 7. Arena. I. Repolho, Hugo Miguel Varela. II. Pontifícia Universidade Católica do Rio de Janeiro. Departamento de Engenharia Industrial. III. Título.

CDD: 658.5 
Dedico este trabalho a minha esposa Angélica Nogueira Miranda. 


\section{Agradecimentos}

Aos meus pais por todo o suporte e incentivo na busca dos meus objetivos.

À minha esposa Angélica Nogueira Miranda por sempre estar ao meu lado e que me motivou desde do início do mestrado e por compreender os finais de semana no qual foi necessária dedicação aos estudos.

Ao Prof. Dr. Hugo Miguel Varela Repolho, que por este período foi mais que um orientador provendo todas as oportunidades de participar em seminários e trabalhos.

Aos amigos de sempre pela torcida em especial ao Eduardo Chrispin, Rodrigo Neves, Marcos Britto e Fatima Yukari, por todo o suporte nos trabalhos e nas disciplinas. 


\section{Resumo}

Fernandes, Rafael da Silva; Repolho, Hugo Miguel Varela. (Orientador). Extensão do tempo de ciclo para tempo de jornada: Inclusão do tempo de pátio e aplicação a uma indústria de varejo. Rio de Janeiro, 2017. 77p. Dissertação de Mestrado - Departamento de Engenharia Industrial, Pontifícia Universidade Católica do Rio de Janeiro.

Os modelos e estudos de roteirização presentes na literatura focam, em geral, nos processos ocorridos desde que os veículos saem do centro de distribuição (CD) até ao seu retorno. Esta visão de roteirização da porta para fora do CD acaba por negligenciar uma etapa importante correspondente às operações de movimentação interna do $C D$, a qual tem influência direta na jornada de trabalho das equipes de entrega e consequentemente na produtividade de cada veículo. A importância da etapa das operações de pátio é bem visível quando analisado o fluxo de valor da cadeia de distribuição. A procura de uma melhor gestão do tempo das operações de pátio abre, assim, uma oportunidade de melhoria da eficiência das operações de distribuição. Esta dissertação foca na inclusão do gerenciamento das operações de pátio junto com a roteirização como forma de aumentar a produtividade da empresa e maximizar a utilização de recursos humanos e materiais. O modelo de gerenciamento desenvolvido utiliza simultaneamente técnicas de otimização e de simulação capazes de planejar e acompanhar as operações de distribuição de uma empresa, respeitando as normas trabalhistas e indicadores de qualidade pré-estabelecidos. O modelo busca melhorar o aproveitamento da jornada de trabalho das equipes de entrega embarcadas em cada veículo, através da minimização dos tempos não produtivos de pátio (recebimento, acerto de contas, conferência de carga, check list de veículo, etc.). A minimização do tempo das operações de pátio aumenta a disponibilidade de tempo de jornada de trabalho da equipe de entrega em rota, possibilitando o aumento do número de pedidos atendidos por cada veículo, sem impactar nas janelas de entrega impostas pelos clientes, estouro na jornada de trabalho e indicadores de qualidade. Para elaboração e aplicação deste trabalho, foram utilizados 3 softwares, um de simulação, outro de roteirização e outro de captação de dados em tempo real. A integração dos três permite captar informações da operação, tratar e simular os modelos e realizar roteirização de veículos, incluindo o tempo de pátio na fórmula de Tempo de ciclo do veículo. O modelo de operação desenvolvido foi aplicado na empresa BETA do segmento varejista de bebidas localizada no Centro-Oeste do Brasil. Os resultados obtidos, quando comparados com a atual operação da empresa, representam uma redução de custo no total de R\$ R\$ 685.234,00 com a operação de distribuição. Especificamente, a racionalização do tempo de pátio permitiu uma melhoria de 2:15:15 em redução de filas no fluxo do pátio ao analisar o fluxo de saída e retorno. Teve ainda como consequência a melhoria da produtividade dos veículos passando de uma média de entrega de 25 para 31 entregas por dia.

\section{Palavras-chave} Otimização.

Roteirização; Tempo de Ciclo; Sistema de Distribuição; Simulação; 


\section{Abstract}

Fernandes, Rafael da Silva; Repolho, Hugo Miguel Varela. (Advisor). Extending cycle time to journey time: inclusion of yard time with application to the retail industry. Rio de Janeiro, 2017. 77p. Dissertação de Mestrado - Departamento de Engenharia Industrial, Pontifícia Universidade Católica do Rio de Janeiro.

The models and studies of routing in the literature focus, in general, on the processes that have occurred since the vehicles leave the distribution center (CD) until their return. This vision of routing the door to the outside of the CD ends up neglecting an important step corresponding to the operations of internal movement of the $\mathrm{CD}$, which has a direct influence on the workday of the delivery teams and consequently on the delivery productivity of each vehicle. The importance of the stage of yard operations is well visible when analyzing the value chain flow of the distribution chain. The search for better time management of yard operations thus opens up an opportunity to improve the efficiency of distribution operations. This dissertation focuses on the inclusion of yard operations management along with routing as a way to increase company productivity and maximize the use of human and material resources. The management model developed simultaneously uses optimization and simulation techniques capable of planning and monitoring the distribution operations of a company, respecting the labor standards and pre-established quality indicators. The model seeks to improve the utilization of the workday of the delivery teams embarked in each vehicle, by minimizing non-productive yard times (reception, accounting, cargo check, vehicle check list, etc.). By minimizing patio operations time we increase the time available for the delivery team to operate, and consequently increase the number of requests served by each vehicle, without impacting on the delivery windows imposed by the customers, work and quality indicators. During the elaboration of this work 3 softwares were used, one of simulation, another of routing and one of data acquisition in real time. The integration of the three allows you to capture information from the operation, treat and simulate the models and perform vehicle routing, including yard time in the Vehicle Cycle Time formula. The operating model developed was applied in the BETA company of the beverage retail segment located in the Center-West of Brazil. The results obtained, when compared to the current operation of the company, represent a reduction of cost in the total of $\mathrm{R} \$ 685,234.00$ with the distribution operation. Specifically, the optimization of patio time allowed for a 2:15:15 improvement in queue reduction in the patio flow when analyzing the outflow and return flow. In addition, the productivity of vehicles increased from an average delivery of 25 to 31 deliveries per day.

\section{Keywords}

Rounting; Cycle Time; Distribution System; Simulation; Optimization. 


\section{Sumário}

1. Introdução 13

1.1. Objetivos 16

1.2. Metodologia de pesquisa aplicada 16

1.3. Estrutura da dissertação 19

2. Fundamentação Teórica 20

2.1. Mapeamento do Fluxo de Valor 20

2.2. Teoria de Filas 21

2.3. Teoria da Simulação 26

2.4. TI e Cadeia de Distribuição Logística $\quad 28$

2.5. Transportation Management System (TMS) 30

2.6. Problema de roteirização veicular 32

3. Modelo de tempo de ciclo com variáveis do tempo de pátio 37

4. Softwares Aplicados $\quad 40$

4.1. Arena $\quad 40$

4.2. Roadnet 41

4.3. GreeMile $\quad 50$

5. Pesquisa Ação 52

5.1. Especificação do Problema e seu desenvolvimento 52

5.2. Mapeamento de fluxo do processo de movimentação interna (pátio) 54

5.2.1. Entendimento do comportamento da operação 55

5.2.1.1. Coleta de dados $\quad 55$

5.2.1.2. Análise dos dados $\quad 57$

5.3. Cenário Atual 58

5.3.1. Resultado Simulação Arena (Cenário Atual) 59

5.4. Cenário Futuro 61

5.4.1. Resultado Simulação Arena (Cenário Futuro) 63

5.5. Resultados 65

$\begin{array}{lr}\text { 6. Conclusão } & 69\end{array}$

$\begin{array}{ll}\text { 7. Referências bibliográficas } & 71\end{array}$

Anexo A - Importância da jornada de trabalho no contexto brasileiro 76 


\section{Listas de Figuras}

Figura 1 - Estrutura Básica de um Modelo de Fila 22

$\begin{array}{ll}\text { Figura } 2 \text { - Estrutura das Filas } & 24\end{array}$

Figura 3 - Metodologia para estudo de simulação 27

Figura 4 - Definição de atividade estratégica, tática e operacional 30

Figura 5 - Janela do modulo de roteirização para Estratégia Padrão 43

Figura 6 - Resultado para Estratégia Padrão 44

Figura 7 - Resultado para Estratégia Padrão, com opção de gerado por

Urgência e Ponto de Geração.

Figura 8 - Resultado para Estratégia Padrão, com opção de gerado por

Tamanho e Centroide 45

Figura 9 - Resultado para Estratégia Padrão, com opção de gerado por Cliente mais próximo e Local mais próximo 46

Figura 10 - Resultado para Estratégia Padrão, com opção de gerado por local mais próximo e Tempo adicional em rota 46

Figura 11 - Resultado para Estratégia Padrão, com opção de gerado por Local mais Distante e Distancia do deposito

Figura 12 - Resultado para Estratégia Padrão, com opção de gerado por

Tamanho e Última parada

Figura 13 - Resultado para Estratégia Padrão, com opção de visualização de Clustering Visual

Figura 14 - Resultado para Estratégia Padrão, com opção de visualização de Vizinhança

Figura 15 - Macro fluxo referente ao processo interno de pátio 54

Figura 16 - Monitoramento das atividades de pátio 56

Figura 17 - Modelo para análise do fluxo de pátio, cenário atual, construído no Arena

Figura 18 - Modelo para análise do fluxo de pátio, cenário futuro, construído no Arena

Figura 19 - Mapa do acompanhamento de indicadores 


\section{Lista de Quadros}

Quadro 1 - Problemas de roteirização e sua importância em publicações 33

Quadro 2 - Combinações de métodos recomendados 48

Quadro 3 - Curva de distribuição de probabilidade das atividades 57

Quadro 4 - Dados para input e simulação do cenário futuro 58

Quadro 5 - Resultado simulação cenário atual: Tempo de fila dos processos

$T P_{0}$

Quadro 6 - Resultado simulação cenário atual: Taxa de utilização dos

recursos aplicados $\boldsymbol{T} \boldsymbol{P}_{\mathbf{0}}$

Quadro 7 - Resultado simulação cenário atual: Tempo de fila dos processos

$T P_{f}$

Quadro 8 - Resultado simulação cenário atual: Taxa de utilização dos

recursos aplicados $\boldsymbol{T} \boldsymbol{P}_{\boldsymbol{f}}$

Quadro 9 - Resultado simulado no cenário atual para tempo de Jornada.

61

Quadro 10 - Dados para input e simulação do cenário futuro

Quadro 11 - Resultado simulação do cenário futuro: Tempo de fila dos

processos $\boldsymbol{T P}_{\mathbf{0}}$

Quadro 12 - Resultado simulação cenário futuro: Taxa de utilização dos recursos aplicados $\boldsymbol{T} \boldsymbol{P}_{\mathbf{0}}$

Quadro 13 - Resultado simulação cenário atual: Tempo de fila dos processos $\boldsymbol{T P}_{\boldsymbol{f}}$

Quadro 14 - Resultado simulação cenário atual: Taxa de utilização dos recursos aplicados $\boldsymbol{T} \boldsymbol{P}_{\boldsymbol{f}}$

Quadro 15 - Resultado simulado no cenário futuro para tempo de Jornada

Quadro 16 - Comparação dos resultados simulados pelo Arena 


\section{Siglas}

CD Centro de Distribuição

TI Tecnologia da Informação

MFV Macro Fluxo de Valor

VRP Vehicle Routing Problem

CLT Consolidação das leis do trabalho

SBDI Subseção especializada em dissídios individuais

TST Tribunal superior do trabalho

TMS Transportation management system

FIFO First in first out

FILO First in last out

SIRO Service in random order

ERP

Enterprise resource planning

SCM

Supply chain management

EDI

Eletronic data interchange

SIL

System information logistic

MRP

Material requirement planning

WMS

Warehouse management system

GIS

Geographic information system

GPS

Geo-positioning system

RDFI

Radio frequency indentification

SLA

Service level agrément

KPIs

Key performance indicators

PCC

Problema do carteiro chinês

TSP

Traveling salesman problem

MDVRP Multi depot vehicle routing problem

CARP

Capacitated arc routing problem

VRPSD Vehicle routing problem with Split deliveries

FSVRP Fleet size and vehicles routing problem

HFFVRP Heterogeneous fixed fleet vehicle routing problem

FSMVRP Fleet size and mix vehicle routing problem 


$\begin{array}{ll}\text { PVRP } & \text { Periodic vehicle routing problem } \\ \text { TDVRP } & \text { Time dependent vehicle routing problem } \\ \text { VRPTW ou } & \text { Vehicle routing and scheduling problem with time Windows } \\ \text { VRSPTW } & \\ \text { VRPSTW ou } & \text { Vehicle routing and scheduling problem with "soft” time } \\ \text { VRSPSTW } & \text { Windows } \\ \text { OVRP } & \text { Open vehicle routing problem } \\ \text { DVRP } & \text { Dynamic vehicle routing problem } \\ \text { TDVRP } & \text { Time dependent vehicle routing problem }\end{array}$




\section{1}

\section{Introdução}

A ampliação do mercado e o aumento do número de empresas ofertando produtos e serviços, proporciona ao consumidor uma maior oportunidade de escolha, aumentando a competitividade entre empresas, que para se manterem atrativas e rentáveis, buscam de forma constante aprimorar seus processos, com o objetivo de disponibilizar seus produtos e serviços em diversificados pontos territoriais, com a melhor qualidade e menor custo possível.

Neste contexto a gestão de transporte é parte essencial do sistema logístico, responsável por viabilizar o fluxo de produtos entre todos os elos da cadeia. Segundo Ballou (2010), em geral, o transporte é o elemento mais importante de uma empresa e absorve mais de dois terços do custo logístico.

$\mathrm{Na}$ atualidade, um dos grandes desafios está relacionado com o processo de distribuição física, onde se busca a melhor alternativa de transporte e entrega do produto, com objetivo de otimizar a utilização de recursos e reduzir custo. As atividades relacionadas à distribuição física buscam, cada vez mais, o aprimoramento da qualidade e da produtividade, de forma a garantir um melhor aproveitamento dos veículos e redução dos percursos (Pelizaro, 2000). Em particular a Distribuição Física em áreas urbana, é uma das atividades mais complexas devido ao grande número de ativos e pessoas envolvidas, ao impacto no congestionamento das ruas e às restrições municipais impostas pelas prefeituras que buscam equalizar o fluxo de veículos entre cargas, passageiros e veículos de passeio. Especificamente no Brasil, soma-se a lei $\mathrm{N}^{\circ} 12.619$ que desde o dia 30 de Abril de 2012, obriga que seja cumprido o tempo de jornada de trabalho do motorista.

A grande diversidade de fatores que intervém direta ou indiretamente nos problemas de distribuição em zona urbana tornam o planejamento de uma rede de distribuição um problema muito complexo. Dentro deste tema um dos tópicos mais pesquisados é a roteirização. Pelizaro (2000), evidencia a importância dos problemas de roteirização e programação de veículos, e a sua ligação direta ao custo e à qualidade de serviço que podem ser agregados. Bodin et al. (1983) 
reforça dizendo que para que o processo seja realizado de maneira eficiente, a empresa deve desenvolver o planejamento e a execução da atividade de transporte de forma lógica e eficiente.

A pesquisa sobre os problemas de roteirização gira em torno da formulação de novos modelos capazes de representar a grande diversidade de condicionantes da realidade ou da formulação de métodos de resolução mais rápidos e eficientes. Silva (2007), declara que a grande dificuldade de resolver problema de roteirização está ligada ao grande número de variáveis de decisão existentes no processo. Dada a complexidade dos problemas de roteirização, a solução ótima só é possível para problemas de dimensão muito reduzida, o que não atende a maioria das necessidades diária de uma empresa. Por esse motivo as ferramentas disponíveis no mercado baseiam-se em métodos heurísticos (Cunha, 2001) de resolução aproximada, mas mais célere.

Ainda assim, e apesar da complexidade e diversidade dos problemas estudados pela maioria dos pesquisadores, os modelos desenvolvidos não representam ainda a realidade na sua plenitude. Por um lado, a maioria dos modelos admite ainda cenários estáticos de roteirização - toda informação é conhecida e não pode ser alterada (Silva Júnior, 2013) - o que não corresponde à maioria dos problemas reais. Por outro lado, existem ainda aspectos da realidade não considerados nos modelos.

Um desses aspectos é a inclusão do tempo de pátio no cálculo do tempo de ciclo. Novaes (2004), informa sobre a possibilidade de incluir o tempo de pátio na formulação de tempo de ciclo, porém, tanto quanto os autores puderam averiguar na literatura existente, não foi encontrado nenhum artigo ou trabalho de otimização ou simulação ligada a roteirização que levasse este aspecto em consideração, no caso de distribuição de carga saindo do CD.

A combinação, entre ferramentas que possibilitam o planejamento de rotas e as tecnologias de informação que permitem o acompanhamento e captura de dados e a simulação de todo o processo de distribuição permite introduzir e calibrar novos parâmetros relevantes para o problema de distribuição e em particular para a roteirização. O resultado é uma maior produtividade e eficiência da operação com redução de custos. 
No mercado, é prática corrente aos profissionais de logística basearem-se em tecnologias de informação (TI), e entre elas em softwares de planejamento e roteirização, desenvolvidas para resolver problema de distribuição levando em consideração as características do serviço, produto e área de atendimento. Atualmente existem ferramentas capazes de monitorar e capturar dados de transporte, provendo suporte e auxílio aos gestores logísticos na parametrização dos roteirizadores e, consequentemente, nas tomadas de decisões de cenários que podem ser desenvolvidos através de simuladores.

No Brasil, este tipo de software é utilizado há quase duas década. Contudo, frequentemente a sua aplicação é feita sem respeitar as especificidades locais como sendo as jornadas de trabalho definidas pela lei trabalhista brasileira, ou sem adequar os parâmetros dos modelos à realidade, o que faz com que as soluções encontradas não reflitam a realidade das operações do dia a dia. Esta falta de adequação pode resultar da falta de preparo dos técnicos, falta de dados, desconhecimento real das operações ou acomodação aos hábitos estabelecidos.

Esta dissertação parte do mapeamento do fluxo de valor que identificou as operações de pátio, sendo uma etapa com influência direta na produtividade dos veículos roteirizados. Na prática, o modelo considera o tempo total de atividades da tripulação embarcada no veículo desde o momento do seu registro biométrico diário de entrada no $\mathrm{CD}$ até o registro biométrico de saída. Por outras palavras, este trabalho aborda o modelo de roteirização de uma forma mais ampla, observando as oportunidades existentes no tempo de jornada da equipe embarcada e o ganho em agilizar os tempos de pátio.

A principal contribuição deste trabalho, está no ajuste realizado na formulação ao realizar a extensão da formula do tempo de ciclo, à qual se adicionou de forma explícita o tempo de pátio inicial e final para simulação e criação do melhor roteiro de entrega, podendo desta forma realizar a gestão sobre a jornada de trabalho da tripulação, evitando o estouro de jornada conforme previsto na CLT através da lei No 12.619 (ver Anexo A). 


\section{1}

\section{Objetivos}

O objetivo geral desta dissertação é propor a extensão da formula do cálculo do tempo de ciclo, que normalmente se associa somente ao tempo de tripulação embarcada, para tempo de jornada incluindo explicitamente a componente de tempo de pátio. O estudo pretende mostrar a relevância do tempo de pátio na produtividade e custo total das operações de distribuição.

Adicionalmente definiram-se os seguintes objetivos específicos:

a) Propor a alteração dos parâmetros de entrada de softwares comerciais de roteirização com base na extensão da formula do tempo de ciclo para tempo de jornada, incluindo o tempo de pátio.

b) Apresentar uma proposta de revisão das operações de pátio buscando minimizar o tempo de permanência dos veículos em processo de carga e descarga e a ociosidade das tripulações, com base na teoria de fila e técnicas de simulação.

c) Aplicar o modelo à empresa Beta e comparar os custos finais com os custos da atual operação.

d) Mostrar como os conceitos de mapa de fluxo de valor (MFV), teoria de filas e teoria da simulação podem ajudar na busca do melhor resultado e como a utilização de ferramentas de monitoramento e simulação pode ajudar a operação e garantir uma melhor parametrização do roteirizador.

\section{2}

\section{Metodologia de pesquisa aplicada}

Silva (2004), aponta uma forma clássica de classificação para planejamento de uma pesquisa, com base no ponto de vista quanto à sua natureza, objetivos e procedimentos técnicos.

De acordo com a classificação apresentada, observando o ponto de vista de sua natureza, adotou-se o modelo de pesquisa aplicada, com objetivo de gerar conhecimento para aplicação prática direcionado à solução de um problema específico, como melhoria na distribuição do tempo de jornada da equipe 
embarcada para o processo de entrega e analisando as oportunidades de redução de fila no processo de pátio.

Quanto ao ponto de vista dos objetivos, a pesquisa possui o foco exploratório, que de acordo com a definição de Prodanov (2006) é quando a pesquisa se encontra em uma fase preliminar e tem como finalidade levantar informações sobre o assunto estudado, para delimitar o tema da pesquisa orientando na definição do objetivo e formulação da hipótese. Prodanov (2006) ainda observa que pesquisa exploratórias, assume em geral formas de pesquisas bibliográficas e estudo de casos.

De acordo com a classificação de Silva (2004), quanto aos procedimentos técnicos, esta dissertação apresenta uma pesquisa bibliográfica e pesquisa-ação.

Pesquisa bibliográfica, pois a fundamentação teórica foi elaborada a partir de material já publicado em livros, periódicos e artigos científicos, para construção direta dos temas sobre mapeamento de fluxo de valor, roteirização, simulação e tecnologias de informação em cadeias de suprimentos. Pesquisa-ação, pois conforme Thiollent (1998), a característica de uma pesquisa-ação requer continua intervenção no sistema pesquisado, envolvimento do sujeito da pesquisa na mesma, mudanças seguidas da ação, a partir da reflexão e cumprir 3 requisitos:

a) Objetivo prático: visa contribuir para o equacionamento do problema na pesquisa, a partir de possíveis soluções que auxiliem os agentes. Podemos destacar este objetivo, nos trabalhos realizados em grupo para avaliação do MFV onde foi analisado o fluxo e pontuado pelos agentes os possíveis pontos de melhoria.

b) Objetivo de conhecimento: pesquisa-ação propicia que se obtenha informações de difícil acesso por meio de outro procedimento, e assim, possibilita ampliar o conhecimento de determinadas situações. Neste item, podem-se apontar as alterações sugeridas para o novo modelo de pátio, com objetivo de redução de fila viabilizando aumento de tempo para o processo de entrega.

c) Objetivo de produzir: gerar conhecimento que não seja útil apenas para a coletividade somente envolvida na pesquisa. Este objetivo se faz presente no fato de se compartilhar a melhorias com os demais centros de distribuição da empresa Beta. 
Após estudo das características e objetivos da metodologia da pesquisaação, concluiu-se que o autor e seus colaboradores atuaram diretamente na pesquisa e nas decisões dos novos modelos bem como sua implementação direta em campo.

Seguindo esta estrutura metodológica, esta dissertação através de uma pesquisa-ação, pretende apresentar a importância em considerar os tempos dos processos ocorridos na movimentação interna "pátio" de um centro de distribuição.

Em termos práticos, a metodologia seguida neste trabalho resume-se como descrito em seguida. Esta pesquisa-ação se deu início, através do trabalho de equipe da empresa BETA, ao construir o mapa do fluxo de processos executada diariamente pela equipe de entrega antes de sua saída para rota e após seu retorno de rota. Na sequência, foi realizado a coleta de dados, com suporte do software GreenMile, capturando todos os tempos dos movimentos entre as etapas dos processos. Através da ferramenta input analyser disponível no software Arena, analisou-se o comportamento de cada etapa do processo com objetivo de encontrar a melhor curva de distribuição de probabilidade que representasse seu ritmo de chegada ou atendimento. Com o conhecimento do comportamento dos processos operacionais, aplica-se o software Arena para realizar simulações com objetivo de identificar os possíveis gargalos que pudessem prejudicar a performance operacional. Através da mesma ferramenta de simulação, analisa-se o cenário futuro, com objetivos de eliminar os gargalos e reduzir o tempo de permanência, da tripulação embarcada, dentro do centro de distribuição. Desta forma, aplica-se o ganho de tempo obtido através da melhoria do processo, diretamente no software de roteirização, informando com maior precisão o parâmetro de tempos gastos com saída e retorno de rota, que também podem ser conhecidos como carga e descarga, ganhando com isto maior disponibilidade de tempo para utilizar na construção do roteiro de entrega e viabilizar o aumento na quantidade de entregas por veículo. 


\section{3}

\section{Estrutura da Dissertação}

A dissertação apresenta a estrutura descrita em seguida. O capítulo 1 constitui a introdução do trabalho incluindo a apresentação dos objetivos, metodologia e estrutura da dissertação. O capítulo 2, apresenta a fundamentação teórica pertinente para o problema de distribuição tratado, a saber: Mapa do fluxo de valor, Teoria de filas, simulação e roteirização de veículos. O capitulo 3 introduz o modelo da formulação do tempo de ciclo e a inclusão das variáveis de pátio. O capítulo 4 apresenta a metodologia e os softwares aplicados para desenvolvimento do trabalho: o Roadnet para roteirizar, o Arena para simulação dos cenários e o GreenMile para monitoramento e levantamento dos dados operacionais. O capítulo 5 apresenta a pesquisa ação e define dois cenários de avaliação e resultados alcançados. Finalmente o capítulo 6, apresenta as conclusões obtidas com o trabalho. 


\section{2}

\section{Fundamentação Teórica}

Garantir uma gestão de distribuição eficiente depende do aumento da produtividade da equipe e dos equipamentos, buscando aproveitar ao máximo o tempo de jornada da tripulação. Para tal é necessário mapear em detalhe o processo e conhecer os tempos e movimentos por forma a identificar potenciais gargalos “Filas” e agir de forma preventiva. No capítulo 2, são apresentados os conceitos teóricos que serviram de base para extensão da formula do tempo ciclo para tempo de jornada, bem como o mapeamento e revisão dos processos de um sistema de distribuição. A saber: mapa de fluxo - auxilia a identificar oportunidades nos processos de pátio e distribuição; teoria de fila - auxilia na identificação de gargalos nos processos e como tratá-los; Teoria da simulação auxilia na forma de enxergar o comportamento da operação antes e depois de sua modificação física; TI aplicada à logística - facilita rotinas e o monitoramento de performance operacional; TMS - Transportation Management System - sistemas de gestão ao transporte e finalmente a roteirização de veículos - modelos e métodos que podem combinar a melhor ocupação de carga e roteiro para distribuição.

\section{1}

\section{Mapeamento do Fluxo de Valor}

A procura da eficiência logística baseada nos princípios do sistema de produção visa a eliminar ociosidade de processos. O Mapeamento de Fluxo de Valor (MFV) é uma das ferramentas utilizadas para identificar e mapear os desperdícios dos processos. O MFV foi introduzido por Rother e Shook (1999) é fundamental para a caracterização de cenários presentes e construção de cenários futuro de empresas. Segundo Jones \& Womack (1998), MFV é o simples processo de observação direta do fluxo de informação e de materiais conforme eles ocorrem, resumindo-os visualmente e vislumbrando um estado futuro com melhor desempenho. O mapeamento é uma ferramenta de comunicação, planejamento e 
gerenciamento de mudanças, que direciona as tomadas de decisões das empresas em relação ao fluxo, possibilitando ganhos em indicadores de desempenho.

Fluxo de Valor define-se como toda a ação, que agrega valor ou não, e necessária para viabilizar um produto. Alguns exemplos são: o fluxo de produção desde a matéria-prima até o consumidor final, o fluxo do projeto, da concepção até o seu lançamento, ou no caso de estudo apresentado neste trabalho, o fluxo de pátio, do início até o término da jornada de trabalho da tripulação.

Definido qual produto da empresa se deseja mapear, inicia-se o desenho do estado atual a partir da coleta das informações como: tempos de execução, número de pessoas envolvidas em cada processo, entre outros. O desenho do estado futuro vem na sequência, acompanhado do plano de trabalho e implementação.

SHOOK (1999), coloca que para atingir um resultado satisfatório no MFV, devem-se seguir 3 passos:

a) Família de produtos: a identificação da família de um produto, pois geralmente os consumidores se preocupam com produtos específicos e não com todos os itens produzidos. Desenhar o fluxo de valor para uma família de produtos, geralmente necessita que as barreiras departamentais das organizações sejam transpostas.

b) Desenho dos estados atual e futuro: inicialmente mapeia-se o fluxo como está ocorrendo atualmente, a partir de dados coletados. Esses dados são necessários para o desenvolvimento do estado futuro, que será um mapa com melhorias propostas que visam diminuir desperdícios.

c) Plano de implementação: descreve como se planeja chegar ao estado futuro. Após tê-lo colocado em prática, um outro mapa do estado futuro deve ser desenhado, ou seja, deve ocorrer uma melhoria contínua no nível do fluxo de valor.

\section{2}

\section{Teoria de filas}

O conceito de teoria de filas foi introduzido por Agner Krarup Erlang por volta do ano de 1908 para solucionar o congestionamento no sistema telefônico com objetivo de perder o menor número de ligações possíveis. 
A teoria de filas é um conceito estudado dentro de probabilidade, que através de modelos matemáticos visa estudar a formação de filas com objetivo de demonstrar seu comportamento, tornando possível dimensionar seu sistema evitando gargalos e desperdício.

Ainda de acordo com Monks (1987), a teoria das filas é uma abordagem quantitativa para a análise de sistemas que incluem linhas de espera ou filas. As linhas de espera podem se formar, quando o sistema não tiver capacidade suficiente, para suprir a demanda. Isto porque o tempo de chegada e os tempos de serviço para os clientes são aleatórios e variáveis. A teoria emprega conceitos de processos estocásticos com o objetivo de analisar e prever o comportamento das filas permitindo melhorar a alocação e utilização de recursos.

Os sistemas de filas caracterizam-se, de forma geral, por um processo de chegada de clientes a um sistema de atendimento para receber um ou mais serviços, executados por certa quantidade de servidores. Andrade (2004), define que um sistema de fila pode ser caracterizado por 6 componentes, dos quais 3 são obrigatórios (Processo de chegada, Processo de atendimento e Mecanismo de atendimento), e 3 são não obrigatórios (Capacidade do sistema, Tamanho da População, Disciplina da fila), conforme pode ser observado na figura 1.

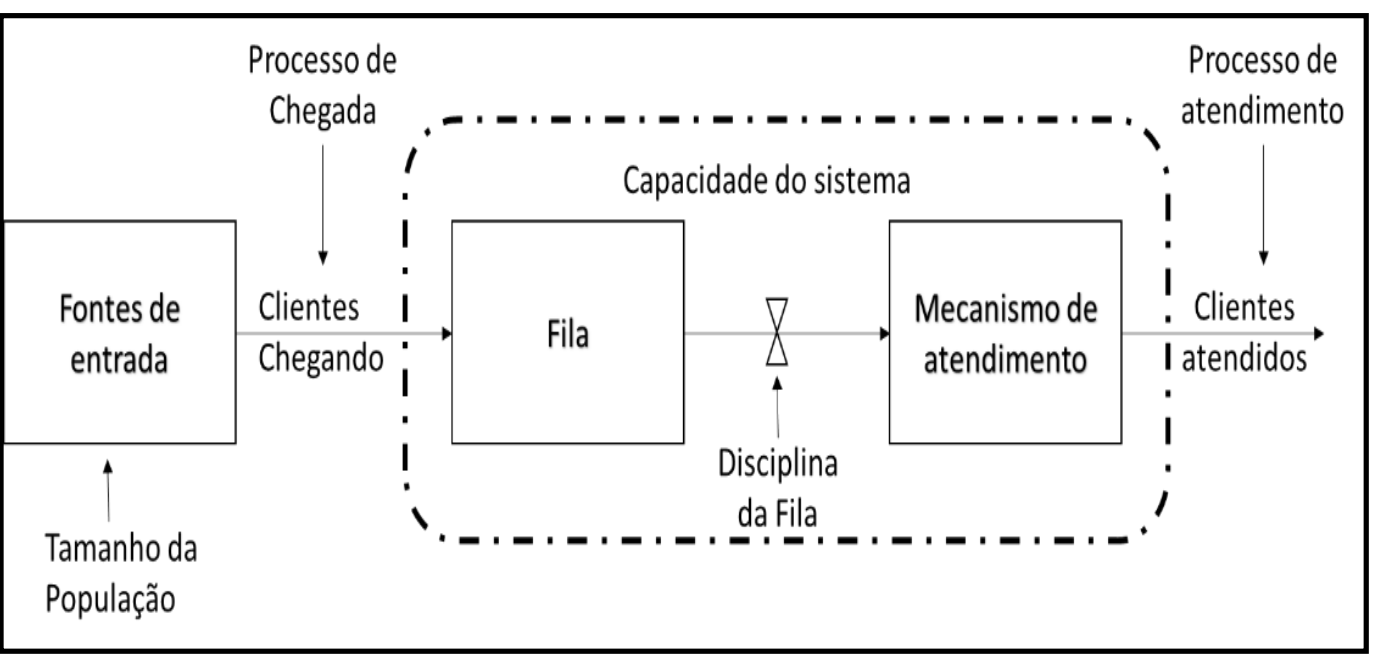

Figura 1 - Estrutura Básica de um Modelo de Fila.

Fonte: Andrade 2004. 
Os 6 componentes podem ser descritos da seguinte forma:

a) Processo de chegada: processo segundo o qual se geram os clientes e é definido pelo tempo entre a chegada sucessiva de dois usuários. A chegada dos clientes pode ser determinística, quando o intervalo ocorre em tempos exatamente iguais, ou aleatória, quando o intervalo de chegada segue uma distribuição de probabilidade possivelmente conhecida.

b) Processo de atendimento: processo correspondente à realização do atendimento e caracterizado por dado tempo e taxa média de atendimento. O processo de atendimento pode ser determinístico ou aleatório.

c) Mecanismo de atendimento: local de atendimento dos clientes, também conhecido como servidores, aonde será definido o número de atendentes disponível para o sistema, podendo ser com 1 ou vários servidores.

d) Capacidade do Sistema: definido pela quantidade de usuários que o sistema é capaz de atender.

e) Tamanho da População: é o potencial de clientes que pode entrar no sistema, podendo ser finito ou infinito.

f) Disciplina da Fila: é a ordem na qual os clientes são escolhidos para o atendimento. Ao lidar com a disciplina da fila, é necessária uma política de atendimentos, sendo a mais utilizada o atendimento ao usuário por ordem de chegada (first in first out - FIFO). Outra possibilidade é o atendimento em que o último a chegar é o primeiro a ser atendido (first in last out - FILO). Finalmente, atendimento em ordem aleatória (service in random order - SIRO) em que o atendimento é feito com base em alguma premissa prioritária, como por exemplo, priorizar a tarefa com menor tempo de processamento.

As informações levantadas através da característica de uma fila, constituem material para análise e aplicação do melhor modelo matemático com objetivo de desenvolver o melhor sistema, que irá trazer o melhor cenário econômico com satisfação do cliente.

Importante também dentro do modelo é conhecer a estrutura da fila, onde de acordo com Aquiliano (2004) um sistema de fila pode ter sua estrutura descrita por um canal único, canais múltiplos ou uma mistura entre os dois, conforme demonstrado na Figura 2. 


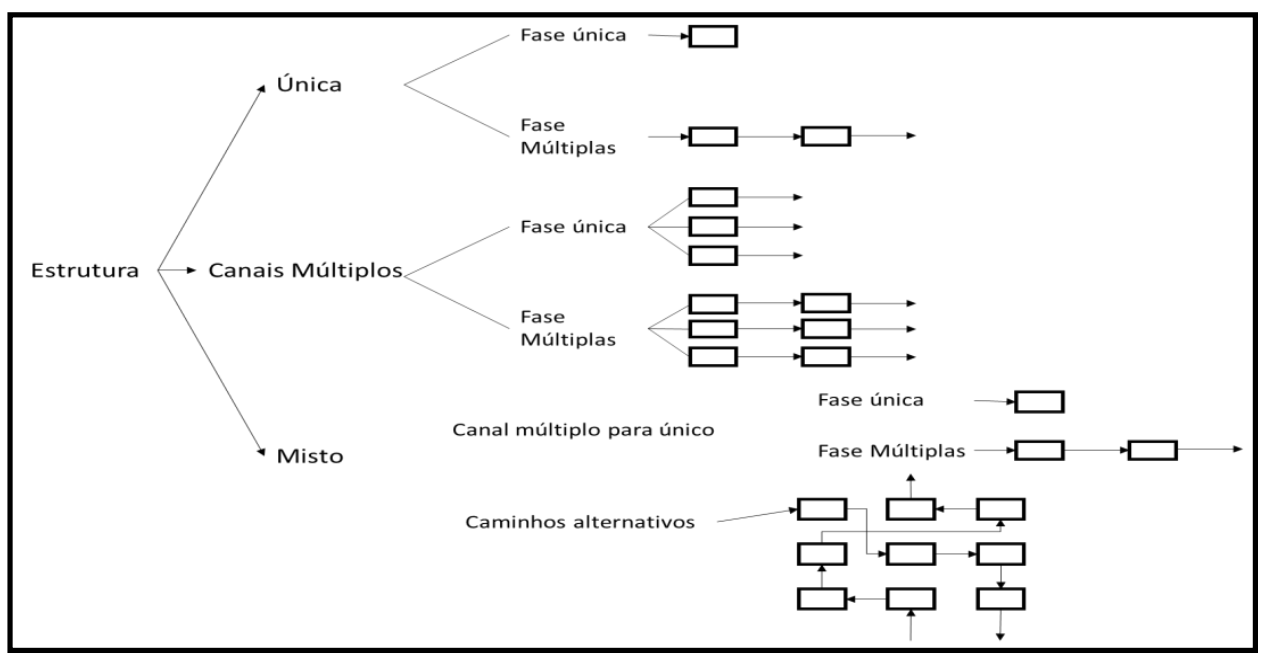

Figura 2 - Estrutura das Filas.

Fonte: Aquiliano (2004).

a) Canal Único, fase única: é o modelo mais simples de fila, havendo já fórmulas diretas para sua resolução, facilmente solucionando por softwares de simulação computacional. O exemplo clássico é aquele de uma loja somente com 1 atendente.

b) Canal único, fase múltiplas: uma fila com múltiplos serviços em sua passagem, podemos citar a lavagem de um carro, onde em uma fila ele executas os diversos atendimentos como: lavar, secar, aspirar, limpa vidro e estacionar. O fator crítico é a quantidade de serviços a serem executados, pois pode vir a gerar filas distintas entre os serviços.

c) Canais múltiplos, fase única: podemos exemplificar ao analisarmos os guichês de um banco ou loja de departamento, onde temos diversos tipos de filas para diversos atendentes, porém estes atendentes podem atender clientes de outras filas, desde que ele não possua mais clientes em sua fila. O mecanismo de gestão deste processo é o mais complicado, pois teremos velocidade e fluxo desigual entre as filas, fazendo com que clientes sejam atendidos antes de outros que chegaram mais cedo. Modificar esta estrutura para atendimento em ordem cronológica de chegada, levaria a um sistema de fila única. Este modelo se aplica para atendimento exclusivos a algumas legislações (idoso, gravidas, deficientes).

d) Canais múltiplos, fase múltiplas: Este caso é similar ao anterior, exceto que dois ou mais serviços são realizados em sequência. A admissão de pacientes em um hospital segue este padrão, porque uma sequência específica de etapas é, geralmente, completada: contato inicial no balcão de admissões, 
preenchimento de formulários, confecção das pulseiras de identificação, obtenção de um quarto, acompanhamento do paciente até o quarto, e assim por diante. Uma vez que vários servidores estão geralmente disponíveis para este procedimento, poderá ser atendido mais de um paciente por vez

e) Misto: Genericamente, podemos ter redes de filas combinando conjuntos de sistemas. Nesse tópico geral, consideram-se duas subcategorias: (1) estruturas múltiplas para canais únicos e (2) estruturas de caminhos alternativos, conforme figura 2.

A pesquisa ação apresentada no capítulo 5 trata de uma estrutura de canal único com fases múltiplas, no qual os veículos ao entrar no pátio realizam em sequência as atividades de:check list dos veículo, verificação de devolução, conferencia de retorno de palete, conferencia de retorno de vasilhame e descarregamento do veículo.

A formação de filas ocorre quando a capacidade de processamento dos recursos disponíveis é menor que a taxa de chegada da demanda. O processo estará em equilíbrio se as taxas médias de chegada e saída forem iguais durante o tempo da análise (PAPADOPOULOS et al., 1993). Para Prado (2014, p.152), estudar o comportamento de filas é uma forma de modificar sistemas nos quais existem gargalos.

$\mathrm{Na}$ atualidade, o conceito de teoria de fila está sendo utilizado para avaliar e estudar a qualidade dos processos, atendimento e dimensionamento em diversas áreas, Rocha (2015) apresenta um estudo para avaliar o fluxo do processo para financiamento habitacional, enquanto Padovan (2016) avalia o atendimento ao público em agência da previdência social e Goldwasser (2016) analisa dimensionamento de leitos públicos para unidade de terapia intensiva. Desta forma observa-se a importância de aplicabilidade da teoria de filas em diversos segmentos.

O mau dimensionamento da estrutura para o atendimento de um processo em fila, pode gerar gargalos, agregando aumento de custo no processo e gerando tempo ocioso de atendentes, clientes e estrutura, gerando assim desperdício. Entre os desperdícios identificados por Ohno (1988 e 1997), na implementação de um fluxo contínuo, destacamos a espera ou fila. Eliminar ou minimizar esse fator 
contribui para a redução da ociosidade e diminuição do tempo do ciclo de carregamento dos veículos para distribuição.

A utilização de ferramentas como o MFV e os princípios de teorias de filas permitem mapear tempos de atividades e fluxos de demanda e, a partir daí, identificar os gargalos da cadeia. Para tal torna-se necessário a implementação e utilização de ferramentas de tecnologia de informação (TI) para monitorar, registrar e armazenar as atividades de movimentação em cada etapa do processo. A TI permite ainda prever quais as melhorias que determinadas alterações podem introduzir no sistema.

Hoje existem softwares capazes de realizar simulações de novos processos e testar antes das alterações físicas a consistência e a redução de desperdício em filas. Nos capítulos 2.3 - Teoria da simulação e 2.4 - TI e Cadeia de distribuição Logística, analisaremos com mais detalhe estes conceitos e suas vantagens quando aplicados a logística.

\section{3}

\section{Teoria da Simulação}

Para Pidd (1998), simulação computacional consiste no uso de um modelo para exploração de conhecimento e experimentação na realidade. Ou seja, a simulação é uma técnica usada para reproduzir um sistema real mantendo características e condições necessárias para a execução do processo, através do uso de um sistema computacional no qual são realizadas algumas adaptações a fim de se obter uma melhor reprodução do sistema, eliminando a necessidade de fazer isso no ambiente real. Santos (2016) entende que a simulação é um processo de experimentação com modelo detalhado de um sistema real para determinar como o sistema irá responder a mudanças em suas variáveis de entrada, enquanto que Ballou (2010) define a simulação computacional como uma técnica adequada para avaliar a dinâmica do fluxo de materiais e informações em operações logísticas. Gordon (1969) define simulação de sistemas como a técnica de resolver problemas acompanhando as mudanças ao longo do tempo em um modelo dinâmico de um sistema.

Ao analisar um modelo de simulação, distinguem-se basicamente três elementos: a entidade, que é qualquer objeto de interesse do modelo, o atributo 
que é uma propriedade desta entidade e a atividade que é qualquer processo que pode causar uma mudança no modelo (Chwif, 1999).

Segundo Pagden (1995), em um mundo de crescente competitividade, a simulação se tornou uma ferramenta muito poderosa para planejamento, projeto e controle de sistemas. Atualmente, ela é considerada uma metodologia indispensável de solução de problemas para engenheiros, projetistas e gerentes. Em suma, a simulação de sistemas é motivada pelos seguintes propósitos:

a) Proporcionar entendimento da operação de um sistema;

b) Desenvolver políticas operacionais para melhorar o desempenho de um sistema;

c) Testar novos conceitos e/ou sistemas antes de sua implementação efetiva;

d) Estudar um sistema sem afetar a sua operação atual.

A Figura 3 sugere uma possível esquematização por etapas de um estudo de simulação.

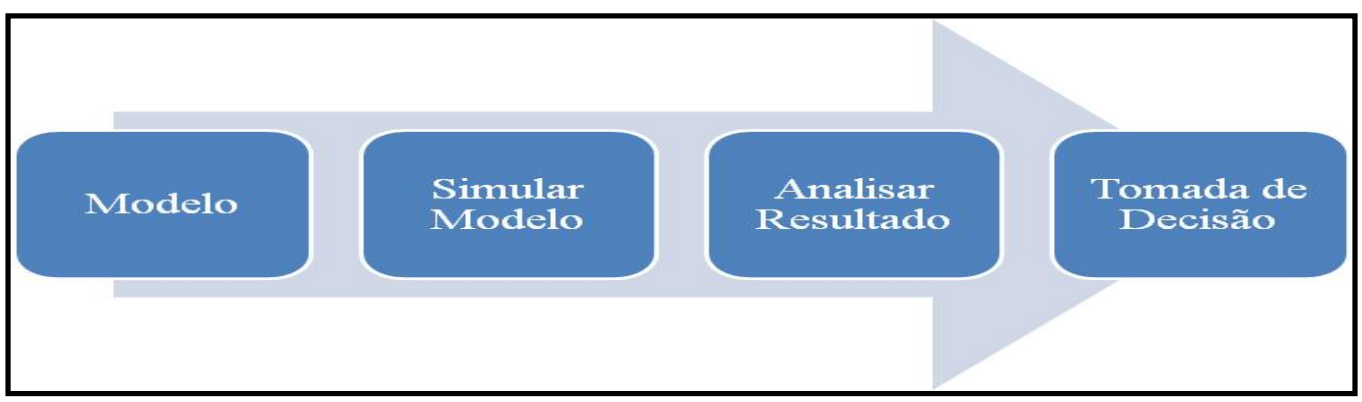

Figura 3 - Metodologia para estudo de simulação.

Fonte: Autor (2017).

Cada uma das etapas pode ser escrita da seguinte forma:

a) Modelo: momento durante o qual se realiza o mapeamento do processo atual analisando todas as variáveis que podem interferir.

b) Simular Modelo: alterar parâmetros do modelo atual, com o objetivo de atingir o melhor resultado da operação.

c) Analisar Resultado: comparar os diversos resultados simulados, bem como seus impactos operacionais e financeiros, com o objetivo de selecionar ou chegar ao melhor equilíbrio. 
d) Tomada de decisão: selecionar o melhor modelo e estudar os próximos passos necessários para realização da implementação das alterações necessárias no processo real.

Dentre os principais simuladores utilizados como ferramenta de simulação, estão os softwares Arena e Promodel (SAKURADA, 2003). Nesta pesquisa ação foi aplicado o Arena, que será abordado no capitulo 4.1 - Arena.

\section{4}

\section{TI e Cadeia de Distribuição Logística}

Brasnki (2008) coloca que para enfrentar um ambiente de negócio cada vez mais complexo, o conceito de logística vem se tornando mais amplo nos últimos tempos, onde nos anos 50 se abordava somente a distribuição física. $\mathrm{Na}$ década de 70 incluiu-se o conceito de gestão de matérias e ressuprimento e no final dos anos 70 incluiu-se também a gestão de movimentação e armazenagem. Atualmente o conceito engloba a totalidade dos fluxos de matérias e informações.

Esta ampliação de escopo da gestão logística tornou-se viável devido ao desenvolvimento tecnológico vivido neste período, principalmente na parte de tecnologia e gestão da informação, o qual possibilita uma maior integração dos processos das empresas e entre empresas. Branski (2008) completa informando que a TI tem grande importância no desenvolvimento das atividades logística, e que as suas aplicações permitem a melhorar o sistema logístico e gerenciamento de forma integrada, deixando-as mais competitivas. LAUDON (2004) defende que a TI está na base da gestão integrada da logística. Em suma, a TI agrega seu valor possibilitando a sincronização das atividades e a gestão de fluxos contínuos sem falhas.

Com a expectativa de ser mais produtiva e competitiva uma vez que permite compartilhar informações entre empresas e coordenar melhor as atividades de forma sincronizada, reduzindo erros operacionais e tornando a gestão dos processos logísticos mais eficientes permitindo a racionalização de processos, redução de estoque e aumento de produtividade das atividades operacionais. Estas conclusões ficam evidentes no estudo realizado por McAfee e Brynjolfsson (2008). Os autores avaliaram quais os fatores que mais 
influenciavam na competitividade das empresas. Entre os fatores analisados estavam: Marketing/Propaganda, Globalização, Pesquisa e desenvolvimento e Investimento em tecnologia da Informação. O estudo teve como conclusão que o investimento em TI apresentou maior correlação em casualidade como fator de diferenciação competitiva. A TI contribui decisivamente para o avanço na performance logística.

Entre os tipos de softwares comerciais com maior impacto na performance logística destacam-se: Enterprise Resource Planning (ERP), Supply Chain Management (SCM), Eletronic Data Interchange (EDI) e System Information Logistic (SIL). Em seguida define-se sucintamente cada uma destas ferramentas.

- Enterprise Resource Planning (ERP): trata-se de um sistema integrado de gestão desenvolvido nos anos 90, com finalidade de integrar e coordenar os processos internos do negócio. Ao receber um pedido, o ERP realiza toda a rotina de acessar estoque, localiza informações do produto, histórico do cliente e informações dos pedidos anteriores, entre outros (Laurindo, 2000)

- Supply Chain Management (SCM): foi desenvolvido para complementar as deficiências do ERP. O SCM suporta a gestão de relacionamento entre empresas, integrando a cadeia entre clientes, produtos, fornecedores e distribuídos dentro do seu processo logístico.

- Eletronic Data Interchange (EDI): é um sistema de envio e recebimento de documentos eletrônicos padronizados entre empresas.

- System Information Logistic (SIL): SIL são sistemas que medem, controlam e gerenciam as operações logística. Existem diversos módulos para gerenciamento de sub-processos da operação logística. Entre os mais conhecidos destacam-se: Material Requirement Planning (MRP), Warehouse Management System (WMS), Geographic Information System (GIS), Geo-Positioning System (GPS), Radio Frequency Identification (RDIF) e o Transportation Management System (TMS).

O TMS é um software de gestão de frotas. Pela relevância que tem no escopo do trabalho realizado nesta pesquisa já que trata diretamente das atividades operacionais voltadas a gestão transportes envolvendo o processo de pátio e 
roteirização, será analisado em detalhe no subcapítulo 2.5 - Transportation Management System (TMS).

\section{5}

\section{Transportation Management System (TMS)}

O TMS auxilia a gestão de transporte dentro da cadeia de suprimentos, garantindo a ligação direta entre seus fornecedores e clientes. Através de suas diversas funcionalidades, o TMS auxilia na gestão de transporte em níveis estratégico, tático e operacionais. A Figura 4 ilustra as atividades ligadas à gestão de transportes em cada nível de decisão.

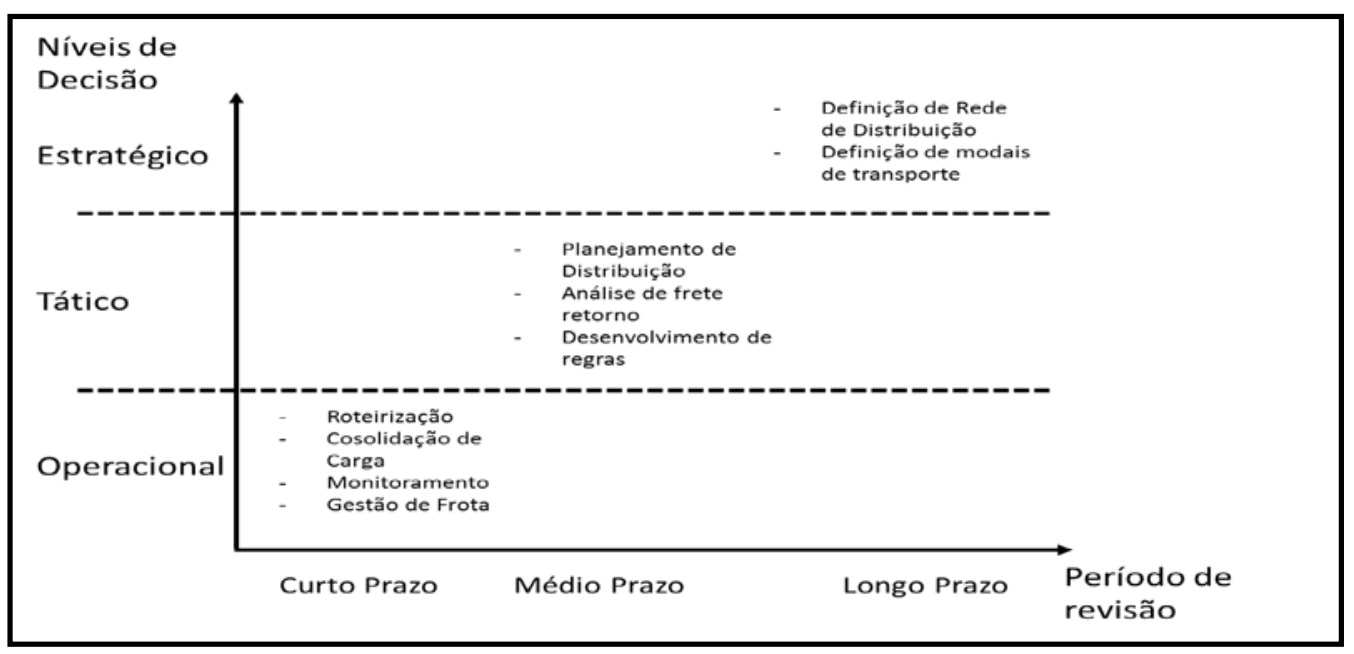

Figura 4 - Definição de atividade estratégica, tática e operacional.

Fonte: Marques (2002).

Ao analisar a figura 4, conclui-se que a pesquisa ação relatada no capítulo 5 envolveu o âmbito Tático e Operacional do TMS, visto a necessidade de desenvolvimento de novas regras para o processo de roteirização.

Para suportar estas tomadas de decisões e auxiliar o operacional nas atividades diárias, a TI auxilia a logística através de funcionalidades desenvolvidas no TMS, como: consolidação de carga, expedição, emissão de documentos, entregas e coletas, rastreabilidade da frota, rastreabilidade dos produtos, apoio à negociação, planejamento de rotas e utilização com definição de modal e equipamentos, gestão de custos, gestão de SLA (Service level agreement) e controle e manutenção da frota. 
Marques (2002) define que a estrutura das funcionalidades do TMS se dividi em 4 grupos, são eles: Monitoramento e gestão de eventos, Apoio à negociação e auditoria de frete, Planejamento e execução e Controle e manutenção de frota.

- Monitoramento e gestão de eventos: Permite maior visibilidade da operação logística através de um painel de controle com status atualizados e KPIs (Key Performance Indicators) da operação. Desta forma é possível acompanhar continuamente os eventos e tomar decisões em tempo real. A ferramenta emite automaticamente alertas de possíveis atrasos, publica status do realizado e calcula automaticamente indicadores pré-definidos. Diferentes funcionalidades permitem aderência às necessidades diversas de cada cliente, podendo gerir operações de pátio (tempo de carga e descarga), agendamento de doca, controle de fluxo de veículo no pátio, monitoramento de entrega, gestão de horas trabalhadas. A ferramenta de monitoramento e gestão utilizada neste trabalho foi o aplicativo GreenMile na gestão e controle dos inputs (ver subcapítulo 4.3 - GreeMile). Um aspecto importante para garantir a qualidade do mecanismo de input de dados é a adequação e customização da ferramenta às necessidades específicas de cada empresa.

- Apoio à Negociação e auditoria: O foco deste módulo é a automação de atividades administrativas, como envio, recebimento e conciliação de informações sobre as entregas realizadas e respectivos custos, controle de pagamento de frete e gestão de dados para suporte da negociação de serviço. Assim, torna-se possível reduzir a incidência de erros operacionais e liberar tempo da equipe da área Logística para atividades estratégicas. Os principais relatórios são: geração de préfatura, conciliação de fatura e geração de relatórios de custo e KPIs.

- Planejamento e Execução: são aplicações capazes de determinar rotas de distribuição e os tempos de parada em cada ponto, propondo os roteiros mais eficientes e com menor custo para cada operação de acordo com um conjunto de restrições que vão desde o veículo, ao cliente e ao meio onde circulam. O software utilizado para o efeito no presente trabalho foi o Roadnet sobre o qual se escreve no subcapítulo 4.2. A propósito de roteirização inclui-se o subcapítulo 2.6 Problemas de roteirização veicular. 
- Controle e manutenção de frota: são ferramentas que realizam o controle e gestão dos custos das frotas, realizando a gestão de consumo por km/rodado, controle de pneus, rodízio de pneus, manutenção corretiva, manutenção preventiva, mantendo o histórico do veículo para melhor tomada de decisão sobre o equipamento.

A redução de custo na gestão de transporte é de grande importância, visto que o transporte é, em geral, a maior componente de custo logístico, representando cerca de dois terços do custo logístico total (Ballou, 2010). Desta forma, ganhos de produtividades podem ser atingidos através da utilização do TMS e suas funcionalidades. Isso justifica a atenção dada a problemas de roteirização e veículos na literatura.

\section{6}

\section{Problemas de Roteirização Veicular}

O objetivo dos problemas de roteirização veicular ou também conhecidos como VRP (Vehicle Routing Problem) é otimizar o planejamento da rota de forma que a demanda dos clientes seja atendida sem violar as restrições definidas (Assad, 1988). Já Subramanian (2012) afirma que os problemas de roteirização de veículos consistem em encontrar as rotas de menor custo, levando em consideração as restrições existentes para atender aos clientes.

Silva (2007) apresenta um levantamento de problemas clássicos de VRP bem como suas definições. Entre outros vale a pena destacar: MDVRP - multi depot vehicle routing problem (Tavares, 2003), CARP - capacitated arc routing problem (Vianna e Gomes, 2006), VRPSD - vehicle routing problem with split deliveries (Dror e Trudeau, 1990), FSVRP - fleet size and vehicles routing problem (Belfiore, 2006), HFFVRP - heterogeneous fixed fleet vehicle routing problem (Tasan \& Gen, 2012), FSMVRP - fleet size and mix vehicle routing problem (Tasan \& Gen, 2012), PVRP - periodic vehicle routing problem (Campbell \& Wilson, 2014), TDVRP - time dependent vehicle routing problem (Belfiore, 2006), VRPTW ou VRSPTW - vehicle routing, and scheduling, problem with time windows (Solomon,1986 e 1987), VRPSTW ou VRSPSTW - 
vehicle routing, and scheduling, problem with "soft" time windows (POTVIN,1993).

Os problemas relacionados a roteirização de veículos são um dos temas mais discutidos e estudados no campo de pesquisa operacional quer pela sua complexidade quer pela sua diversidade. A pesquisa relacionada com o problema de VRP sejam extensões ou métodos de resolução, crescem a cada ano. Segundo Eksioglu (2009) o número de artigos publicados por ano relacionados com esta temática cresce à taxa de 6\% ao ano. Seu estudo revelou que entre o período de 1959 a 2008, 1021 artigos de revistas trataram o VRP como tema principal.

Conforme demostrado por Silva (2007) são várias as extensões de VRP existentes, o que pode dificultar a busca literária por um determinado tema. Nesse sentido, Braekers (2016) realizou um estudo com o objetivo de realizar uma classificação dos artigos existentes. O autor analisou 277 artigos entre o período de 2009 a 2015 para criar uma taxonomia e analisar a tendência de VRP na literatura. Analisando os VRPs mencionados acima por Silva (2007), dentro da taxonomia apurada por Braekers (2016), conseguimos identificar o grau de importância, pela quantidade de publicações, que possui cada problema apresentado. Os resultados estão sintetizados na Quadro 1.

Quadro 1 - Problemas de roteirização e sua importância em publicações.

\section{Classificação Braekers} (2016)

\section{Problemas Clássicos de Roteirização apontados por Silva (2007)}

\section{Relevância literária, com base no quantitativo de presença relativa em artigos}

Capacity consideration

Multiple depots (3.4.2)

Stochastic Demands

(2.3.2)

Split deliveries allowed (2.2.1)

Heterogeneous vehicle

(3.8.3)

Multi-period time horizon

(2.7.2)

Time-dependent travel time

Time Window

$\begin{array}{cc}\text { VRP, CARP } & 90.52 \% \\ \text { MDVRP } & 11,01 \% \\ \text { SVRP } & 6,12 \% \\ \text { VRPSD } & 6,12 \% \\ & \\ \text { FSVRP, HFFVRP, } & 16,51 \% \\ \text { FSMVRP } & \\ \text { PVRP } & 8,87 \% \\ \text { TDVRP } & 3,06 \% \\ \text { VRSPTW ou VRPTW, } & 37,92 \% \\ \text { VRSPSTW ou VRPSTW } & \end{array}$

Fonte: Adaptado de Braekes (2016). 
Existem diversos estudos voltados para as diversas variações de VRP. Caceres (2014) apresenta em sua pesquisa cerca de 60 trabalhos que abordam VRP. O estudo realizado por Braekes (2016), aponta a tendência de variantes para VRP que incluem restrições e informações da vida real, tornando os modelos mais próximos da realidade e das necessidades operacionais apresentadas pelas empresas. Neste contexto, nos últimos anos destacaram-se 3 derivações de VRP: OVRP - open vehicle routing problem (Repoussis 2010), DVRP - dynamic vehicle routing problem (Pilac 2013), TDVRP - time depende vehicle routing problem (P. Belfiore 2006).

- OVRP (open vehicle routing problem): Segundo Repoussis (2010) o OVRP que é um conhecido problema de otimização combinatória que aborda o serviço de um conjunto de clientes usando uma frota homogênea de veículos não capacitados. O objetivo é minimizar o tamanho da frota e a distância percorrida. No caso do OVRP, os veículos não são obrigados a retornar no CD após realizar a visita no último cliente), esta solução se encaixa para soluções no qual a frota é terceirizada, no qual a equipe embarcada não faz parte direta da empresa.

- TDVRP (time dependent vehicle routing problem): P. Belfiore (2006) define este problema como sendo uma variação do problema clássico de rotas de veículos, em que o tempo entre dois pontos (quer seja entre dois clientes ou entre um depósito e um cliente) depende não só da distância entre eles, como da hora do dia a que o percurso se realiza. Neste tipo de problema, o objetivo é minimizar o tempo para a realização do percurso.

- DVRP (dynamic vehicle routing problem): O DVRP (também conhecido como VRP on-line ou em tempo real), apresenta um aumento considerável de interesse dos pesquisadores nos últimos anos, segundo Breakes (2016) cerca de 4,28\% dos artigos classificados discutem DVRP. Segundo Pilac (2013) os avanços tecnológicos levaram a um aumento no interesse em problemas de roteamento dinâmico de veículos. O dinamismo de incluir novas demandas de acordo com a solicitação dos clientes, demostra bem a situação real operacional. Hong (2012) aponta que não há definição ou formulação disponíveis para o DVRP. 
Apesar de alguns autores mencionarem a importância do tempo de pátio (e.g. Novaes, 2004), nenhum deles o inclui explicitamente nas formulações. A inclusão do tempo de pátio tem impacto na jornada de trabalho real da tripulação. A extensão da formulação do tempo de ciclo para tempo de jornada pode ser aplicada a todas as derivações de VRP apresentadas. Alguns autores já iniciam estudos com foco no tempo de jornada da tripulação (Goel, 2009; Kok, Meyer, Kopfer, \& Schutten, 2010; Rancourt, Cordeau, \& Laporte, 2013), porém ainda buscam minimizar os riscos e otimizar operação através de algoritmos com previsibilidade considerando somente variáveis externas ao Centro de Distribuição. Vale ressaltar que o estudo de Goel (2009) foi aplicado à operação de distribuição para o modal aéreo, que difere bastante do comportamento de distribuição Urbana.

Esta dissertação, irá apresentar o ganho operacional viabilizado pela inclusão dos tempos de movimentação no pátio de carga no planejamento da distribuição. Este trabalho é especialmente importante após a aprovação da lei $\mathrm{N}^{\circ}$ 12.619 que desde o dia 30 de Abril de 2012, onde obriga que seja cumprido o tempo de jornada de trabalho da tripulação, neste caso motoristas e ajudantes de entrega. Um resumo do Decreto de lei que rege esta implementação é fornecido no Anexo A.

Os problemas de roteirização veicular são considerados de alta complexidade, classificados como NP-hard (Penna, 2012), para o qual algoritmos heurísticos e híbridos são considerados como abordagens adequadas para uma boa solução em tempo computacional aceitável. Algoritmos exatos são apenas eficientes para instâncias de pequeno problema, dificultando assim a solução do problema e a obtenção do cenário ótimo. Os modelos de solução com métodos exatos, não conseguem prover uma solução eficiente de acordo com necessidade de mercado já que são restringidos a números muito pequenos de nós (clientes) a serem atendidos na rede de distribuição e não conseguem absorver a demanda existente de diversas restrições.

Nesse contexto, os softwares comerciais de roteirização usam heurísticas como métodos de resolução, que mesmo não apresentando a solução ótima, apresentam soluções eficientes tendo em conta o tempo de resolução e as necessidades de resposta reais. Uma das vantagens é a possibilidade de resolução de problemas reais de grande escala, atendendo assim às necessidades do 
mercado. O software utilizado neste estudo de caso para criação dos roteiros é o RoadNet. Uma explicação mais detalhada do software é fornecida no sub-capítulo 4.2 - RoadNet desta dissertação. 


\section{3}

\section{Modelo de tempo de ciclo com variáveis do tempo de pátio}

O tempo de ciclo corresponde à duração de um percurso completo de distribuição de um veículo desde que sai do centro de distribuição de partida até que chega ao centro de distribuição final. Tradicionalmente considera por isso todos os tempos de deslocamento entre clientes, entre centros e clientes, e tempos parados para atendimento dos clientes. De acordo com a literatura o tempo de ciclo é definido da seguinte forma (Novaes, 2004):

$$
\boldsymbol{T C}=D \boldsymbol{I}_{1}+\sum_{i \in I} \boldsymbol{T} \boldsymbol{E}_{i}+\sum_{i \in I}^{N-1} \sum_{j \in I: j=i+1}^{N} D P_{i j}+D F_{N}
$$

onde se define:

$\boldsymbol{I}=\{\mathbf{1}, \ldots, \boldsymbol{N}\} \quad$ Conjunto ordenado de clientes a serem atendidos por um veículo de distribuição.

TC Tempo de Ciclo - é o tempo total em horas de trabalho do veículo, desde sua saída na portaria do CD até seu retorno e chegada à portaria do CD.

$\boldsymbol{D I}_{1}$ Deslocamento Inicial - é o tempo do deslocamento realizado entre o CD e o primeiro cliente a ser atendido, $\boldsymbol{I}_{\mathbf{1}}$.

$\boldsymbol{T}_{\boldsymbol{i}} \quad$ Tempo de Entrega - é o somatório dos tempos de entregas que foram realizadas pelo veículo em cada cliente $\boldsymbol{i} \boldsymbol{\epsilon} \boldsymbol{I}$

$\boldsymbol{D} \boldsymbol{P}_{\boldsymbol{i j}} \quad$ Deslocamento entre Pontos consecutivos - é o somatório dos tempos referente ao deslocamento realizado entre cada $I=\{1, \ldots, N\}$.

$\boldsymbol{D F}_{\boldsymbol{N}} \quad$ Deslocamento Final - é o tempo de deslocamento realizado entre o último ponto de entrega até a chegada ao Centro de distribuição. 
Ao analisar a necessidade de melhoria na produtividade do processo de distribuição física, nota-se a existência de outras variáveis não contempladas. Em geral, os modelos de VRPs são voltados a buscar eficiência na otimização dos roteiros de entrega e se preocupam em solucionar restrições urbanas e de clientes como: janelas de entrega, coleta e entrega, restrições de circulação, vias bloqueadas, entre outras. Porém, com a necessidade de gerenciar o processo de distribuição respeitando a jornada de trabalho da tripulação, se faz necessário minimizar os tempos das rotinas de pátio realizada pela da tripulação.

A formulação clássica proposta não inclui explicitamente o tempo de pátio, o qual corresponde a uma parcela considerável da jornada de trabalho das equipes. Ainda assim, Novaes (2004) aponta que se podem incluir tempos parados no centro de distribuição, tanto na saída quanto no retorno, subdivididos em tempo fixo na partida e no retorno para o centro de distribuição:

- Tempo na saída: processo como recepção de ordem, colocação do veículo no local de carregamento, conferência de carga, enlonamento, check list de mecânica no veículo, etc.

- Tempo no retorno: processo de controle de embalagens vazias, check list das condições do veículo, prestação de conta referente as entregas, etc.

O tempo de pátio, especialmente para empresas de distribuição, é um parâmetro muito importante, que afeta diretamente o tempo de jornada de trabalho da tripulação e consequentemente a produtividade dos veículos de entrega. Por esse motivo propõe-se realizar a extensão da formula do cálculo de tempo de ciclo no qual o parâmetro de tempo de pátio é explicitamente contemplado. Para começar substituímos o conceito de tempo de ciclo por tempo de jornada (TJ) definido como o tempo total em horas de trabalho da tripulação, desde sua entrada no centro de distribuição para o início de sua jornada de trabalho, até sua saída do centro de distribuição finalizando o término de sua jornada de trabalho. O tempo de pátio é adicionado como início e fim da jornada de trabalho com os parâmetros $\mathbf{T P}_{\mathbf{0}}$ e $\mathbf{T P}_{\mathrm{f}}$, respectivamente. 
$\boldsymbol{T P}_{\mathbf{0}} \quad$ Tempo de Pátio Inicial - é o tempo onde se registra a entrada da equipe embarcada no centro de distribuição, abrindo seu ponto para o início de sua jornada de trabalho até o registro de saída da equipe embarcada na portaria para o início de rota.

$\boldsymbol{T P}_{\boldsymbol{f}} \quad$ Tempo de Pátio Final - é o tempo onde se registra na portaria o retorno da equipe embarcada de rota até o registro de ponto formalizando sua saída do Centro de Distribuição.

O novo modelo assume a seguinte forma:

$$
T J=T P_{0}+D I_{1}+\sum_{i \in I} T E_{i}+\sum_{i \in I}^{N-1} \sum_{j \in I: j=i+1}^{N} D P_{i j}+D F_{N}+T P_{f}
$$

O modelo apresentado busca aproximar a modelagem da realidade a fim de obter maiores eficiências no planejamento dos esquemas de roteirização e controle de jornada de trabalho conforme a lei $\mathrm{N}^{0} 12.619$.

Esta dissertação busca apresentar um modelo de trabalho no qual mostra não só a necessidade de trabalhar com o software de roteirização, mas também com softwares que podem auxiliar no conhecimento dos aspectos operacionais, coletando e simulando dados que podem auxiliar na parametrização do roteirizador bem como atualização periódica destes parâmetros. Levando em consideração a formulação de TJ, ou seja, tempo de jornada da tripulação. 


\section{4}

\section{Softwares Aplicados}

Neste capitulo serão apresentados os softwares de mercado utilizados na pesquisa ação levada a cabo no decorrer desta dissertação para suporte ao levantamento de dados e simulação dos cenários, bem como à geração de roteiros de entregas.

\section{1}

\section{Arena}

Segundo Prado (2010), o sistema Arena é um dos softwares de simulação mais utilizados em todo o mundo, tanto por empresas como por universidades. Uma das vantagens do programa é a utilização de dados estocásticos na simulação. Com isso, não são utilizados valores médios para parâmetros no modelo, mas sim estatísticas geradas a partir de uma base de dados coletada previamente.

Banks et al. (1984), afirma que o Arena trabalha com módulos interligados entre si em uma região denominada área de trabalho. Uma vez interligados, é possível que as entidades percorram os módulos a partir de um determinado evento. Para facilitar a visualização e compreensão do modelo ao longo do seu desenvolvimento, é feita a descrição de um fluxograma da entidade ao longo do sistema onde cada um dos módulos possui um conjunto específico de parâmetros que podem ser configurados de acordo com as especificações do sistema.

Segundo Fioroni (2007), o funcionamento conceitual do modelo adotado, acontece da seguinte maneira: o usuário descreve durante a construção da modelagem todos os elementos estáticos como recursos e outros, incluindo também as regras de comportamento a serem seguidas. Ao se iniciar a simulação, os elementos dinâmicos (entidades) interagem com os elementos estáticos e circulam conforme as regras que foram adotadas. 


\section{2}

\section{Roadnet}

O Roadnet Transportation Suit é um conjunto de ferramentas inteligentes e integradas que auxiliam empresa nos processos de, Planejamento e Otimização de Rotas de Vendas, Roteirização Diária das Entregas, Carregamento Otimizado dos Veículos de Entrega, Rastreamento e Monitoramento via GPS da Frota e Análise de Informações Gerenciais de Roteirização.

O Roadnet está dividido em seis módulos, são ele:

- Módulo de Administração: O Módulo de Administração permite que o administrador do sistema configure informações como usuários do sistema, grupos de usuários, privilégios de acesso e regiões de acesso. É neste módulo que se configuram os níveis de acesso e privilégios que cada usuário pode ter.

- Módulo de manutenção e cadastro: O Módulo Manutenção compreende todas as informações sobre a operação, tais como: clientes, funcionários, equipamentos e outras informações que serão usadas ao planejar suas rotas. Chamamos essas informações de parâmetros operacionais. O Módulo Manutenção é usado inicialmente para configurar essas informações e depois para manter atualizadas as informações do sistema.

- Módulo de Manutenção de Mapas: O RoadNet traz em dois de seus módulos (Manutenção e Roteirização) uma ferramenta que completa todos os processos. Essa ferramenta, chamada de MAPA, traz a característica de possibilitar a visualização de resultados diretamente em mapas que contém as mesmas proporções da realidade, uma vez que são confeccionados em escala. Nestes mapas, o usuário consegue visualizar os clientes já geocodificados, os depósitos que serão utilizados no processo de roteirização, os caminhos possíveis para se chegar ao cliente, os melhores caminhos que poderão ser adotados nas rotas.

- Módulo de Importação: O módulo Importação permite importar informações: clientes, extensões de cliente, pedidos, equipamentos, motoristas, outros itens de manutenção, dados de um computador de bordo e até mesmo rotas criadas em outros pacotes de software. Permite também configurar um processo 
para importar automaticamente informações em um horário especificado do dia, eliminando a necessidade de importá-las manualmente.

- Módulo de Roteirização: O Editor de roteirização permite roteirizar pedidos diários e avaliar rotas subsequentes, bem como alterá-las conforme necessário. Você pode atribuir equipamentos e motoristas às rotas no Editor e exportar as informações de roteirização resultantes para o host. Tanto as rotas padrão quanto as diárias podem ser criadas no Editor de roteirização. As rotas diárias podem ser padrão, dinâmicas ou uma combinação de ambas.

o Rotas padrão: são aquelas com clientes específicos em uma determinada ordem. Quando os pedidos forem recebidos para qualquer uma das paradas da rota, essa parada será incluída na rota do dia. Um dos benefícios de usar rotas padrão é saber quais motoristas estão indo para quais clientes em cada dia. As rotas padrão também costumam exigir menos manutenção. O inconveniente é que as rotas padrão geralmente são mais caras.

o Rotas dinâmicas: são criadas do zero, considerando apenas os pedidos daquele dia. Elas costumam ser mais baratas, mas exigem mais manutenção, pois as informações do cliente, do equipamento e do motorista devem ser atualizadas. O Roadnet permite criar uma combinação de rotas padrão e dinâmicas.

- Módulo de Relatório: O Roadnet produz relatórios sobre as rotas que podem ser fornecidos aos motoristas, bem como relatórios de gerenciamento que podem ser utilizados para avaliar a eficiência das rotas. Alguns desses relatórios incluem: manifestos e itinerários de motoristas, tempo de atendimento e de percurso real vs. planejado, retornos ao cliente, custo de entrega no cliente, horário de abertura/fechamento e desempenho da janela de atendimento, utilização de recursos e desempenho do motorista.

Um ponto muito importante, é a estratégia que poderá ser adotada para roteirização. Neste caso há recomendação do roadnet onde se aponta a oportunidade de se combinar algumas alternativas de metodologias, conforme mencionado no capitulo 2.6 - Problemas de roteirização veicular. Na figura 5 a sugestão apontada, quando se seleciona a estratégia Padrão. 


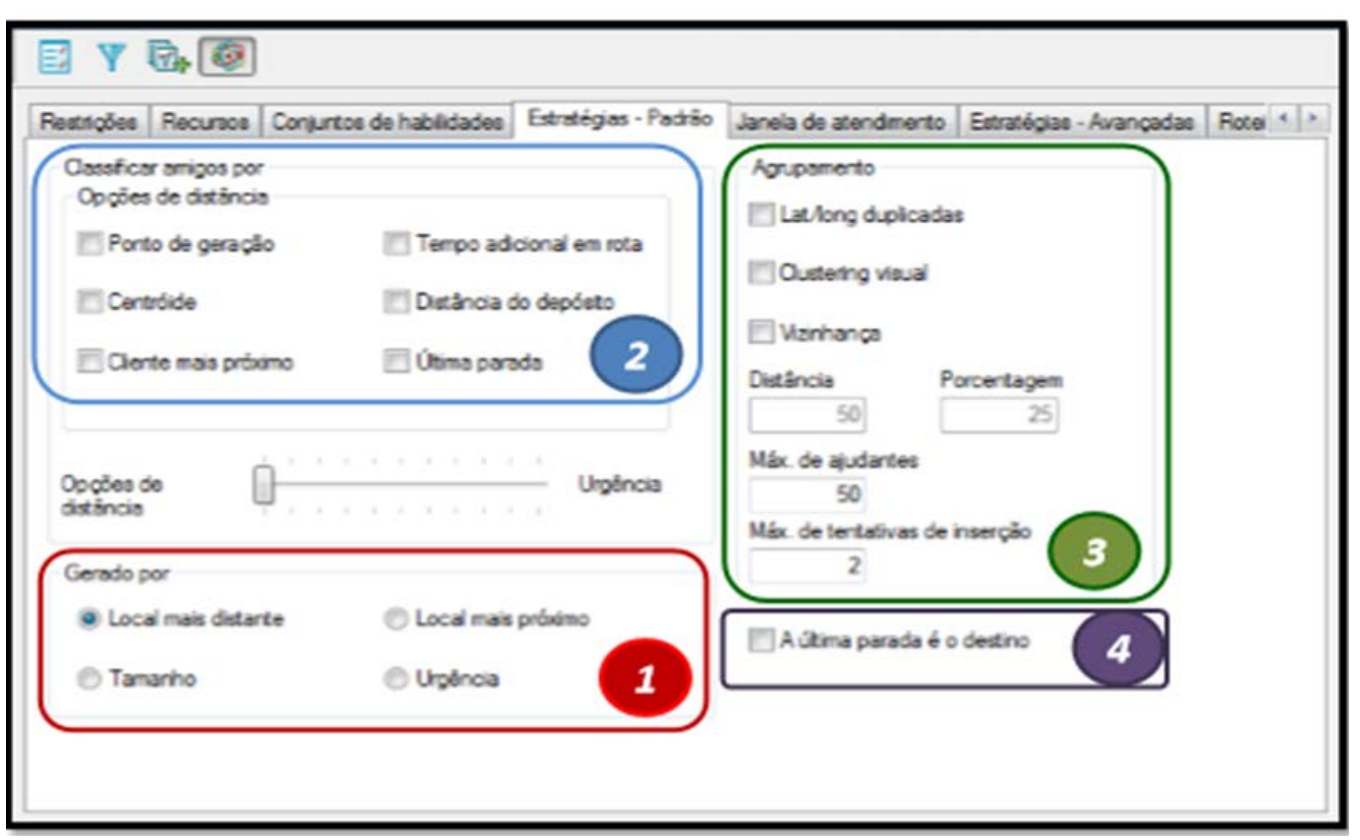

Figura 5 - Janela do modulo de roteirização para Estratégia Padrão.

Fonte: Roadnet.

Na Estratégia Padrão, conforme figura 5, é permitida a seleção das estratégias para criação das rotas. É possível selecionar opções de classificação de paradas nas rotas, balanceamento do fator predominante na criação das rotas (opções de distância ou urgência), permite que seja selecionado como a rota será gerada. Permite selecionar fatores de agrupamento na criação das rotas e configurar para que a última parada das rotas seja o destino ou a origem.

Na figura 5 estão assinaladas 4 marcações de quadrantes (1, 2, 3 e 4). O quadrante 1 é a área onde se pode definir qual será o modelo a ser seguido pelo algoritmo, ou seja, calcular rota levando em consideração o atendimento ao cliente mais distante, o mais próximo, o com maior carga ou o com maior urgência. Já no quadrante 2, temos a oportunidade de selecionar qual será o melhor sequenciamento, através do ponto de geração, centroide, cliente mais próximo, tempo adicional em rota, distância do deposito ou última parada. No quadrante 3, define-se o melhor modelo de agrupamento para visualização do processo de roteirização com clientes plotados no mapa e no Quadrante 4 é possível definir se o último cliente é a parada final ou se deverá retornar ao ponto de partida. Esta opção espelha bem a possiblidade levantada nos modelo OVRP (open vehicle routing problem) apresentados no capitulo 2.6 - Problemas de roteirização veicular. 
Em seguida apresentam-se alguns exemplos e explicações de como se comporta a roteirização de acordo com a seleção realizada.

- Resultado para Estratégia Padrão: A figura 6, mostra os cenários quando apontada a opção do cenário do $1^{\circ}$ quadrante, mostrando no caso os clientes com Local mais distante, Local mais próximo, maior Urgência e tamanho. Partindo deste princípio, pode-se analisar os cenários que podem ser criados ao optar, no quadrante 2, por selecionar os locais de atendimento por ordem de distâncias.

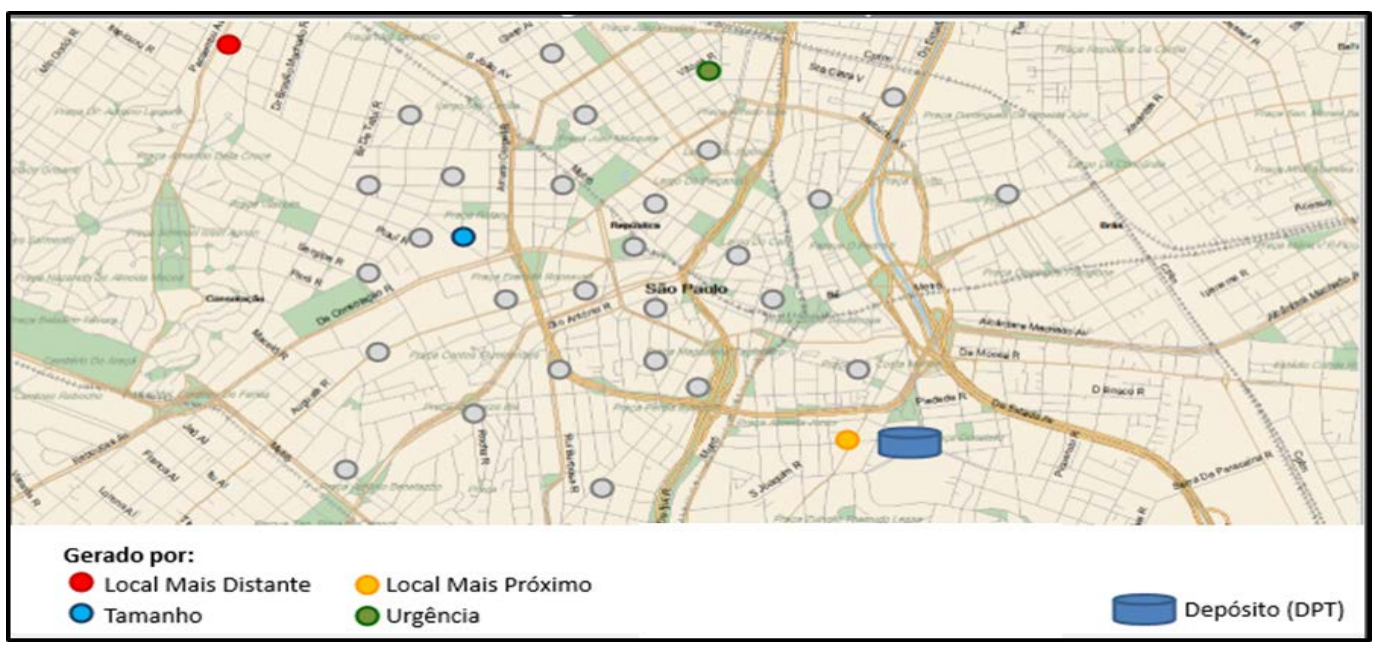

Figura 6 - Resultado para Estratégia Padrão.

Fonte: Roadnet.

- Ponto de Geração: Ordena a lista de possíveis paradas pelo tempo de percurso a partir do ponto inicial da rota. A figura 7 mostra o resultado de uma combinação entre a escolha da opção do quadrante 1 (ponto de geração) e opção do quadrante 2 (urgência). Onde há uma restrição de atendimento com urgência e desta forma o RoadNet, lista as possíveis paradas adotando como premissa o tempo de percurso, similar ao identificar o caminho mínimo até o nó (cliente) desejado. 


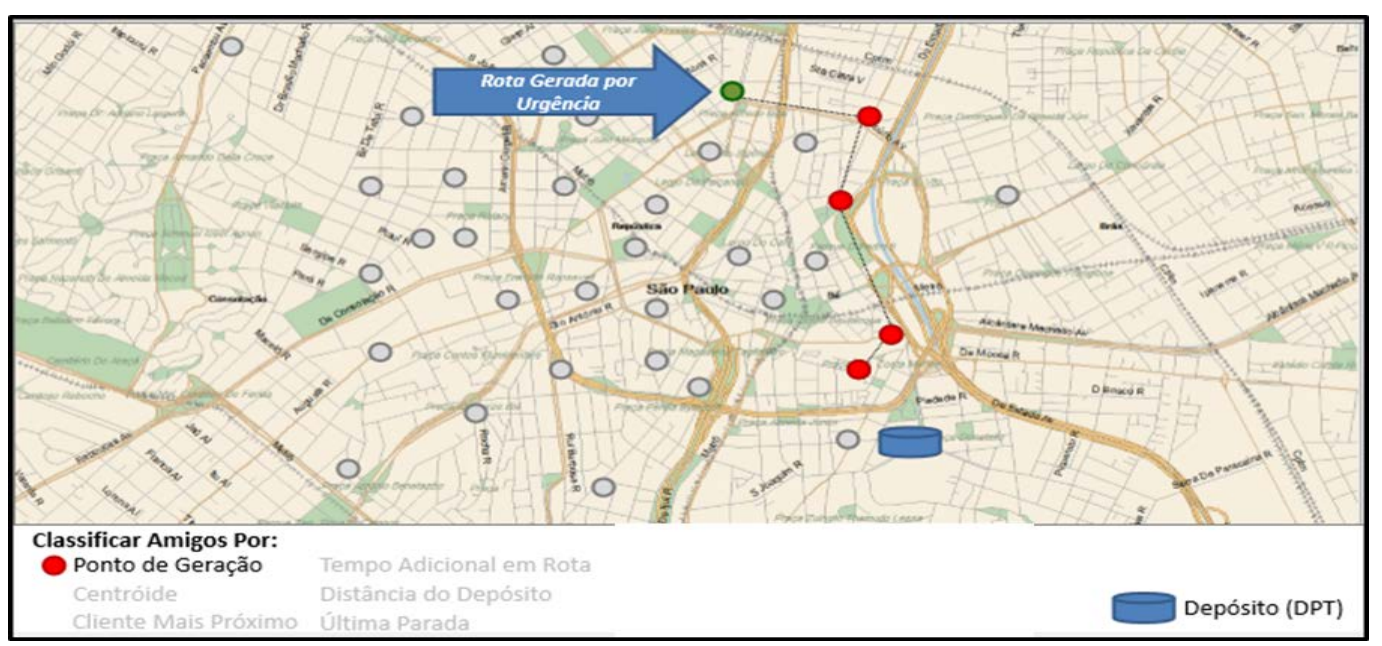

Figura 7 - Resultado para Estratégia Padrão, com opção de gerado por Urgência e Ponto de Geração.

Fonte: Roadnet

- Centroide: Ordena a lista de possíveis paradas pela distância do centroide, epicentro, da rota. A figura 8 mostra o resultado de combinações entre a escolha da opção do quadrante 1 (centroide) e opção do quadrante 2 (tamanho), onde se ordena o sequenciamento de atendimento através do nó (cliente) contido no epicentro, realizando uma varredura e montando a rotas.

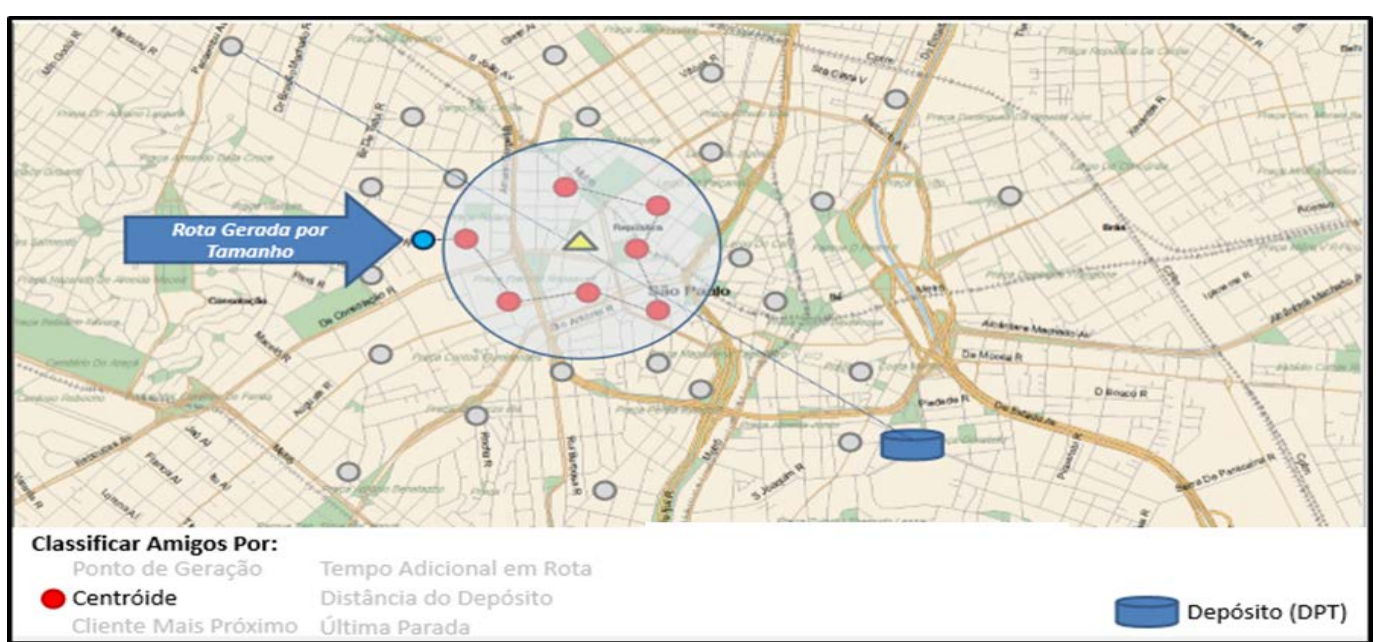

Figura 8 - Resultado para Estratégia Padrão, com opção de gerado por Tamanho e Centroide.

Fonte: Roadnet

- Cliente mais próximo: Ordena uma lista de paradas pela distância da parada mais próxima na rota. A figura 9 mostra o resultado de combinações entre as escolhas das opções do quadrante 1 (cliente mais próximo) e opções do quadrante 2 (local mais próximo), onde se ordena o sequenciamento de 
atendimento através do nó de origem (CD), selecionando o nó (cliente) mais próximo e assim sucessivamente.

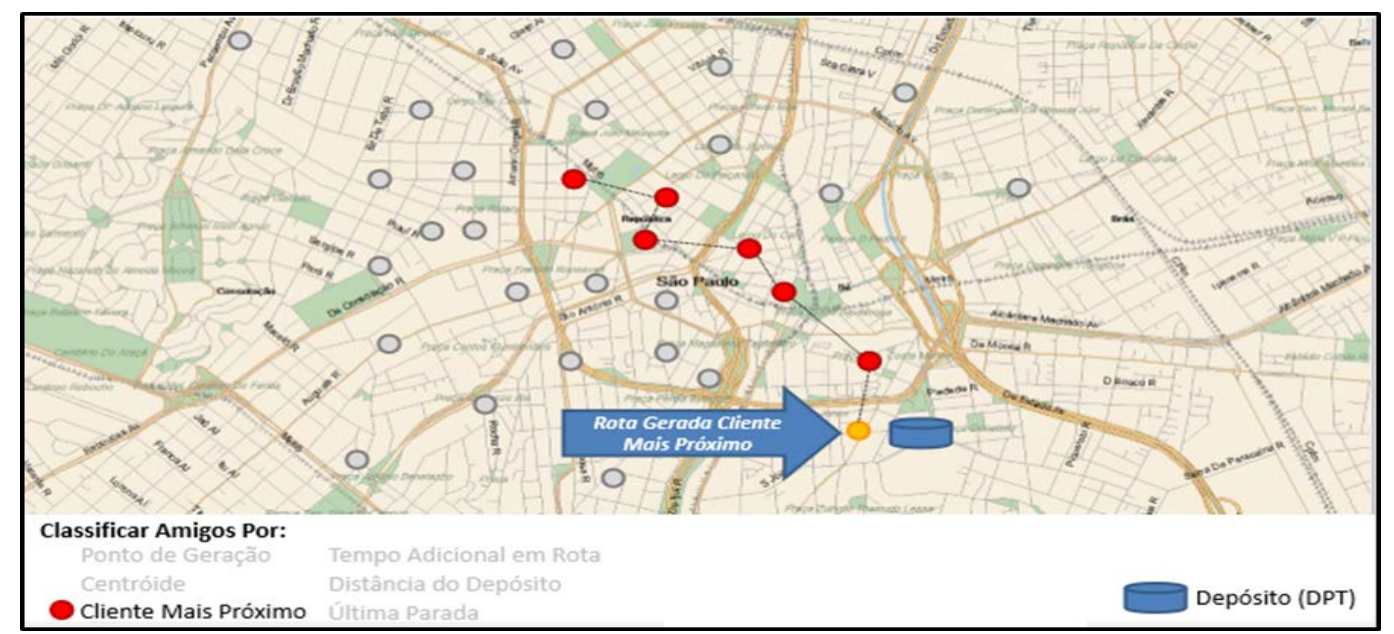

Figura 9 - Resultado para Estratégia Padrão, com opção de gerado por Cliente mais próximo e Local mais próximo.

Fonte: Roadnet.

- Tempo adicional em rota: Ordena a lista de paradas pela quantidade de tempo de percurso adicionado a rota. A figura 10 mostra o resultado de combinações entre a escolha da opção do quadrante 1 (tempo adicional em rota) e opção do quadrante 2 (local mais próximo), onde se ordena o sequenciamento de atendimento através do nó de origem (CD), selecionando o nó (cliente) mais próximo e assim sucessivamente até encontrar a restrição de jornada de trabalho ou tempo pré-determinado.

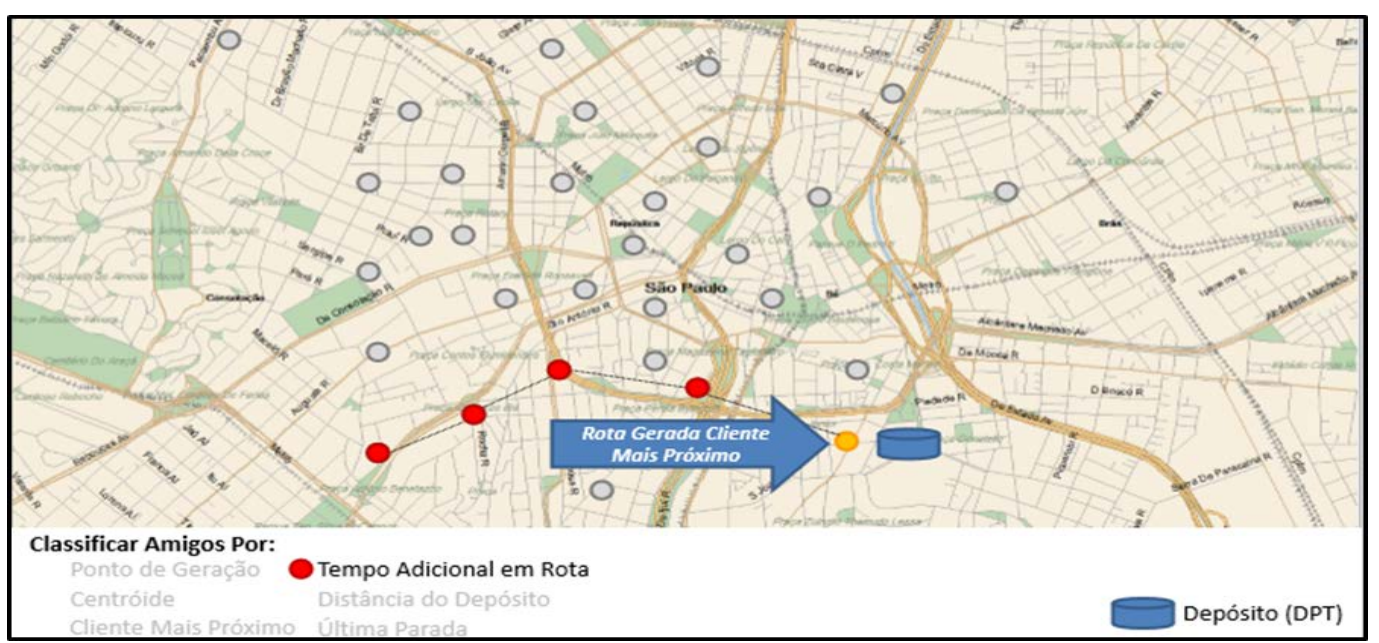

Figura 10 - Resultado para Estratégia Padrão, com opção de gerado por local mais próximo e Tempo adicional em rota.

Fonte: Roadnet. 
- Distância do depósito: Ordena uma lista de paradas pela distância para o deposito. A figura 11 mostra o resultado de combinações entre a escolha da opção do quadrante 1 (distância do deposito) e opção do quadrante 2 (local mais distante), onde se ordena o sequenciamento de atendimento através do nó de origem (CD), selecionando o nó (cliente) mais distante do nó de Origem (CD), porém na sequência de realização para identificação do nó (cliente) mais próximo ao seu nó (cliente) antecessor.

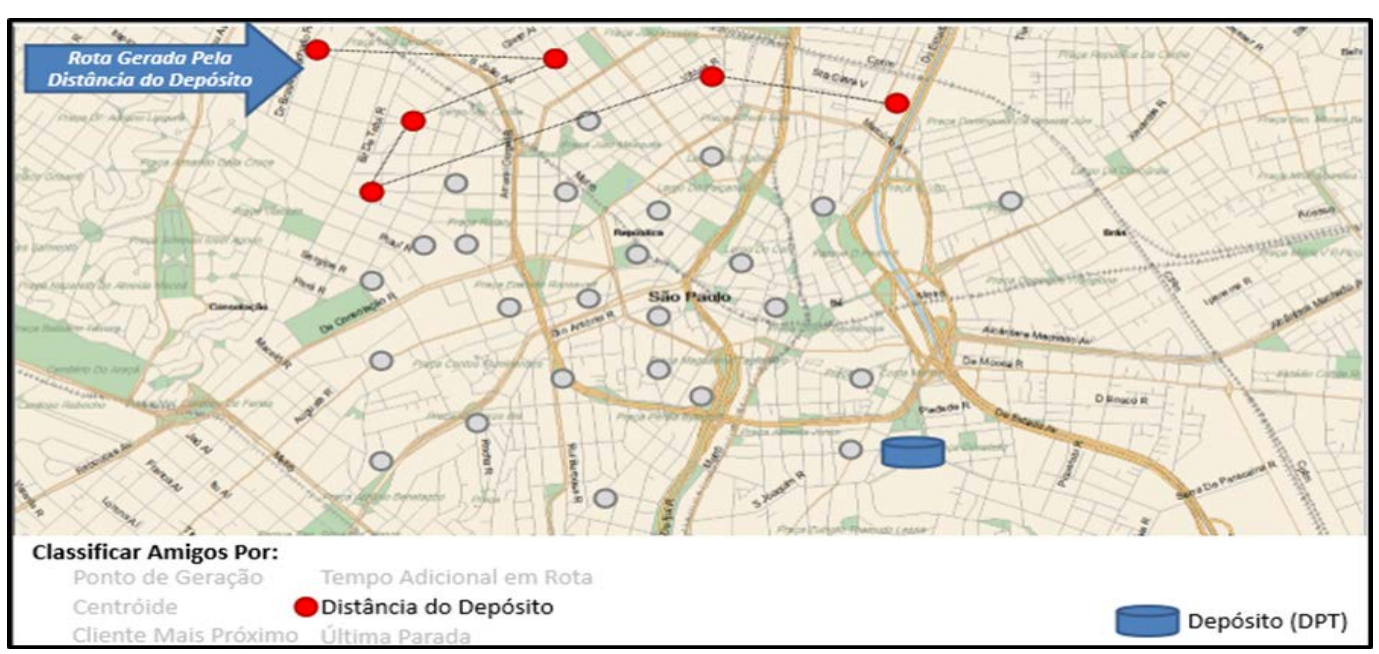

Figura 11 - Resultado para Estratégia Padrão, com opção de gerado por Local mais Distante e Distancia do deposito.

Fonte: Roadnet.

- Última Parada: Ordena pela distância da última parada na rota. A figura 12 mostra o resultado de combinação entre a escolha da opção do quadrante 1 (ultima parada) e opção do quadrante 2 (tamanho), onde se ordena o sequenciamento de atendimento através do nó de origem (CD), selecionando o nó (cliente) que seria atendido por último dentro do roteiro. Similarmente ao que acontece no método de varredura, onde o primeiro passo é alocar os clientes nos veículos e depois definir a ordem de atendimento, neste caso a ordem está sendo definida pelo cliente com maior restrição (peso, custo, valor, tempo) a ser atendido 


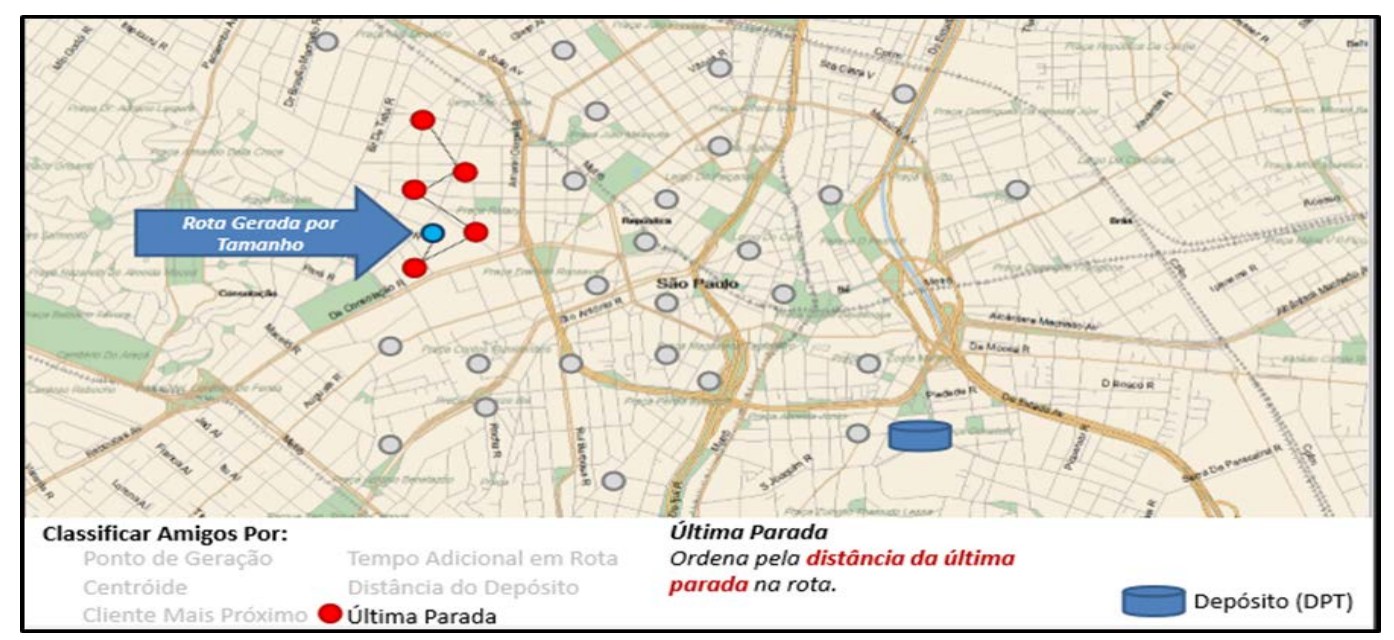

Figura 12 - Resultado para Estratégia Padrão, com opção de gerado por Tamanho e Última parada.

Fonte: Roadnet.

É necessário ter cuidado com as combinações a serem realizadas, pois algumas não são convergente e podem não apontar a melhor solução para operação. O próprio Roadnet aponta quais as combinações recomendadas e as não recomendadas, tal como sumariado no Quadro 2.

Quadro 2 - Combinações de métodos recomendadas.

\begin{tabular}{|c|c|c|}
\hline Classificar amigos por: & Gerado por: & $\begin{array}{c}\text { Combina ou Não } \\
\text { combina }\end{array}$ \\
\hline Tempo adicional em rota & Distância do depósito & Não combina \\
\hline Centroide & Cliente mais próximo & Não combina \\
\hline Ponto de geração & Cliente mais próximo & Combina \\
\hline Ponto de geração & Centróide & Combina \\
\hline
\end{tabular}

Fonte: Material de treinamento RoadNet.

Centroide deve ser usado quando ocorre paradas que estão próximas, como acontece dentro de áreas urbanas com densidades de pontos de entrega muito próximo um dos outros.

Cliente mais próximo, deve ser usado quando as paradas estão mais afastadas, como acontece maioritariamente em áreas rurais. 
Estas são opções de combinações para busca do melhor resultado, porém não se pode esquecer das opções apresentadas no quadrante 3 , pois quanto melhor a forma de visualização do agrupamento dos pontos maior o potencial de atingir o melhor resultado.

- Clustering Visual: realiza agrupamento do cliente, através do critério geográfico, conforme pode ser observado na figura 13.

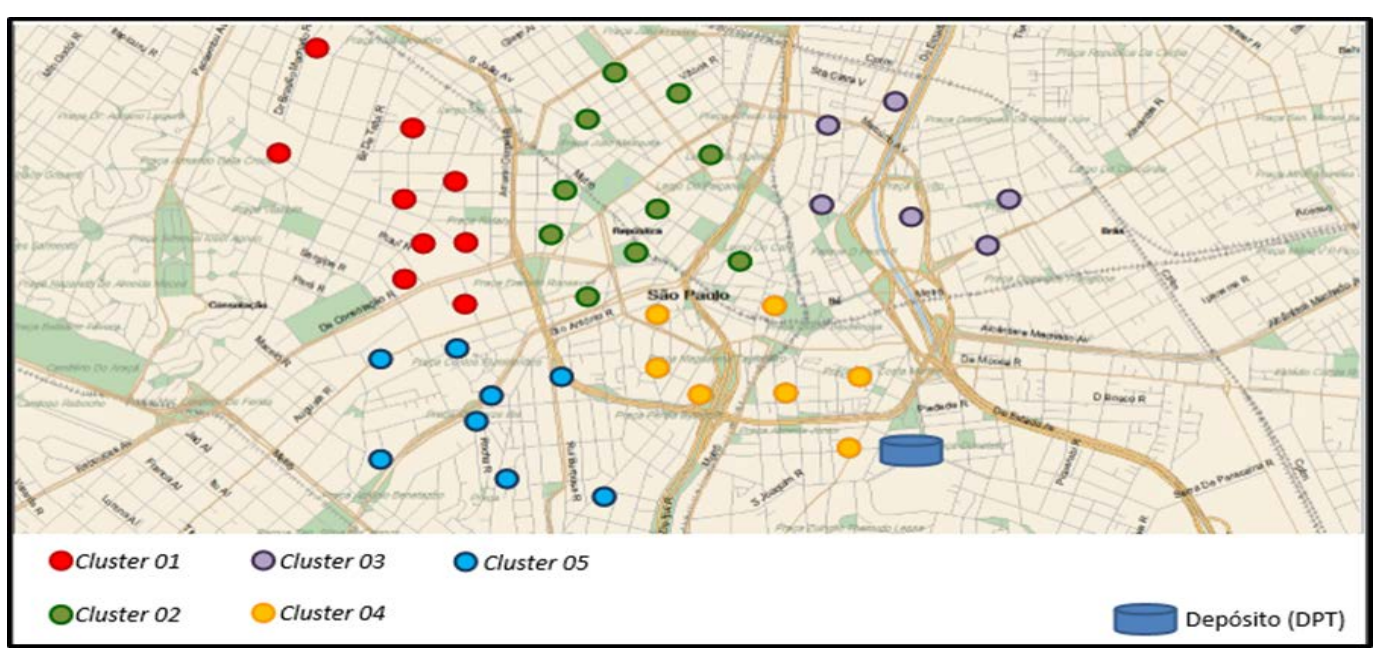

Figura 13 - Resultado para Estratégia Padrão, com opção de visualização de Clustering Visual.

Fonte: Roadnet;

- Vizinhança: insere um raio de abrangência para cálculo de distância e o percentual de clientes para inclusão no novo raio, conforme pode ser observado na figura 14 .

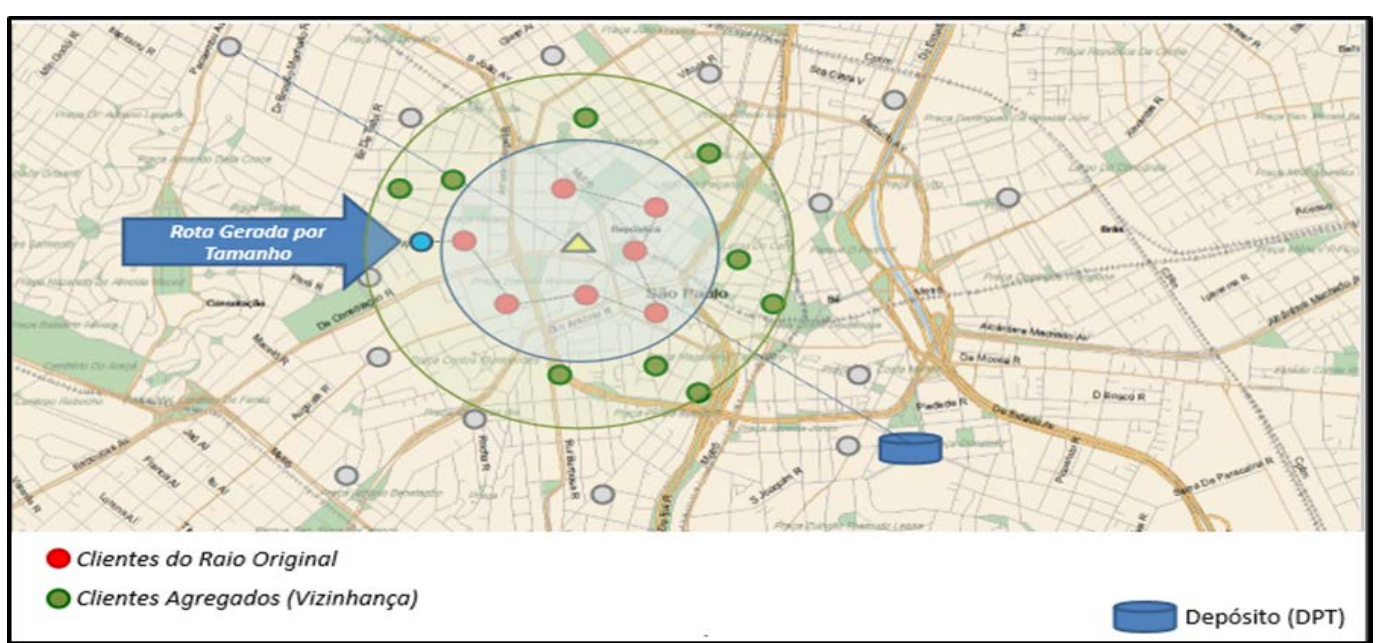

Figura 14 - Resultado para Estratégia Padrão, com opção de visualização de Vizinhança.

Fonte: Roadnet. 
Pode ser observado que o RoadNet é altamente customizável e oferece informações sobre as condições de estradas e de vias, disponibilidade de automóveis e de motoristas, restrições de janela de atendimento e, inclusive, horário de duração da rota. Seu algoritmo é capaz de combinar todas estas restrições e desenhar o melhor roteiro de entrega. Observe que o mesmo software, é capaz de roteirizar uma demanda que possui padrões de diversos modelos de VRP.

O Problema abordado nesta pesquisa ação é um tipo VRP com características de frota heterogênea, coleta ou entrega, sem janela de tempo, entregas fracionadas, múltiplos produtos, único deposito e com restrição de circulação em vias e de rotas dinâmica. Desta forma, é imprescindível atualizar os parâmetros. A atualização será preferencialmente feita diariamente, mas também é possível definir período de manutenções. Quando se opta por este modelo, o roadnet mostra que se deve ter atenção aos pontos, como: restrições, recursos, estratégia padrão, janela de atendimento, estratégia avançada, roteirização do código da rota, Auto atribuição, recargas, limites de recargas, pós-processos, retrocessos, sequência padrão e dividir pedidos.

\section{3 \\ GreenMile}

A GreenMile é uma empresa em soluções móveis baseados na nuvem para a indústria de logística e de transportes. As soluções da GreenMile são usadas por empresas em diferentes segmentos com foco em monitorar o desempenho dos seus recursos (caminhões, equipe de entrega, veículos comerciais, etc.), sejam eles ativos ou pessoas, com foco em aumentar a sua eficiência enquanto reduzem os custos globais de logística.

O software da GreenMile pode ser integrado com diversas tecnologias aplicadas à gestão de monitoramento, sendo capaz de realizar o acompanhamento do planejamento realizado pela roteirização e aferindo, em tempo real, podendo prover ao gestor ações imediatas para corrigir qualquer desvio que venha ocorrer durante a operação. Um aspecto relevante é a capacidade de captura de dados operacionais das entregas (pendente, entregue, cancelada, adiada, etc.) bem como dados da expedição (início de jornada do motorista, início de carregamento, 
término de carregamento, saída do veículo, chegada do veículo, início de descarga, término de descarga, fim de jornada do motorista).

O GreenMile possui diversas funcionalidades importantes. Para esta pesquisa-ação vale destacar:

- Smart Geocode: é a forma inteligente de identificar e corrigir automaticamente variação entre um endereço de entrega registrado no seu software de planejamento de rotas e o local onde a entrega de fato ocorre. Com esta solução é possível corrigir os parâmetros de latitude e longitude cadastrados no roteirizado e realizar a correção de cadastro, principalmente no aspecto de entregas em comunidade, no qual há uma grande dificuldade na captura do endereço.

-Atualização de tempo de atendimento: A funcionalidade de Service Time Updates (atualizações do tempo de atendimento) calcula os tempos de atendimento fixo e variável para cada cliente usando dados históricos de entrega. Estas informações podem ser trabalhadas para simulações de cenários em aplicações de softwares de simulação e também para manter o parâmetro de tempo de atendimento do roterizador atualizado.

- Notificação de Eventos: Gerencia problemas na entrega assim que eles ocorram, e antecipa de modo proativo os possíveis problemas nas rotas. Desta forma há condições de informar os clientes quanto ao posicionamento da entrega e a uma previsão de quando ela poderá ocorrer, programando o recebimento e evitando perda de tempo no ato da entrega.

Com o suporte desta tecnologia, temos condições de gerir todo o planejamento de rota montado pelo roterizador, bem como capturar informações da expedição, importantes para construção do tempo de jornada, e mapear ocorrências que podem vir acontecer durante a realização da rota, possibilitando análise para eliminação de futuros riscos. 


\section{Pesquisa-ação}

O objeto de ação deste trabalho é uma empresa de produção e distribuição de bebidas (cervejas, refrigerantes, sucos, energéticos e águas) subsidiária de uma grande companhia mundial, BETA, a qual integra mais de 46 mil funcionários no mundo, e está presente em mais de 15 países. No Brasil a empresa conta com 13 unidades fabris em 11 estados, mais de 20 centros de distribuição próprios e 190 revendas para atender cerca de 600 mil pontos de vendas. Para este trabalho, escolheu-se, especificamente, o CD localizado no Centro-Oeste com capacidade de atendimento para 1.400 entregas diárias, com uma frota de 75 equipamentos de entrega e um time operacional composto de 214 pessoas entre motoristas, ajudantes, conferentes e líderes. Neste capítulo serão apresentadas a empresa, o modelo de gestão de distribuição utilizada atualmente, as etapas do projeto para construção do novo modelo e os problemas relacionados ao mesmo.

\section{1}

\section{Especificação do Problema e seu desenvolvimento}

Após a validação da lei $\mathrm{N}^{\circ} 12.619$ em vigor desde o dia 30 de abril de 2012, o controle do tempo de jornada de trabalho do motorista passou a ser efetivamente controlado. Para tal contribuiu também a aprovação da portaria MTE 1.510/2009 que prevê a obrigatoriedade do uso de ponto eletrônico. Neste contexto, a gestão da equipe de entrega tornou-se mais complexa e restritiva já que obrigatoriamente cada trabalhador fica proibido de exceder a jornada de trabalho em mais de 2 horas (jornada extra máxima), bem como proibido o interstício inferior a 11 horas entre uma jornada e outra, conhecido como intrajornada.

No contexto da nova lei aproveitar ao máximo o tempo de jornada útil disponível para as atividades de entrega tornou-se prioritário para tornar o sistema de distribuição mais eficiente. O problema de estudo desenvolveu-se a partir da identificação do tempo de pátio como sendo um dos gargalos da operação. Assim 
foram analisados os processos de liberação dos veículos para distribuição, bem como no seu retorno, avaliando os processos de movimentação interna no pátio do CD.

Conforme mencionando no capítulo 1.1. Objetivos, pode-se verificar as oportunidades de melhorias no processo, reduzindo os tempos de fila no pátio, ou seja, reduzindo o tempo de permanência, no CD, da tripulação, proporcionando um aumento de horas que viabiliza o aumento na quantidade de entregas a ser alocada por veículo e proporcionar a melhor parametrização do software de roteirização, aumentar a produtividade dos veículos de entrega e reduzir o investimento em ativos ou necessidades de contratação, spot, de terceiros para execução do serviço. Neste processo assumiu-se como premissa a manutenção do nível de serviço e respeito das regras de política de jornada de trabalho.

Para viabilizar a coleta de dados, sobre os tempos e movimentos da equipe de entrega no pátio do CD, a empresa BETA investi na implementação do software GreenMile, desta forma é possível acompanhar a marcação de tempo sobre a rotina do motorista, desde a sua chegada ao CD até ao término de jornada, e visualizar todos seus principais passos como por exemplo: entrada no CD, início de conferência de carga, término de conferência de carga, início de viagem, retorno ao centro de distribuição, início e término de conferência de carga no retorno, fechamento de caixa e saída do CD como término de jornada.

A análise da rotina de percurso dos motoristas forma uma base de dados capaz de prover informações para calibrar os parâmetros do software de simulação Arena, que por sua vez possibilita realizar simulações das rotinas e identificar filas e gargalos, bem como, oportunidades de melhorias.

No capítulo 5.3 - Cenário Atual, será apresentado a simulação realizada pelo software Arena com objetivo de identificar gargalos, filas, em torno do processo da movimentação interna realizada no pátio do $\mathrm{CD}$, no momento da liberação dos veículos para rota e no seu retorno de rota. No capítulo 5.4 - Cenário Futuro, será apresentado as alterações realizadas pela equipe da pesquisa-ação. No capítulo 5.5 - Resultados, será apresentado os resultados e uma comparação entre o cenário proposto e o anterior mostrando os ganhos financeiros, benefícios e oportunidades com os indicadores que forma o nível de serviço. 


\section{2}

\section{Mapeamento de fluxo do processo de movimentação interna (pátio)}

Para entendimento do problema, a equipe construiu o macro fluxo do processo, conforme figura 15, referente à movimentação do pátio, com objetivo de entender atividades desenvolvidas internamente. O macro fluxo também auxilia a entender os pontos necessários para coleta dos dados e análise da operação.

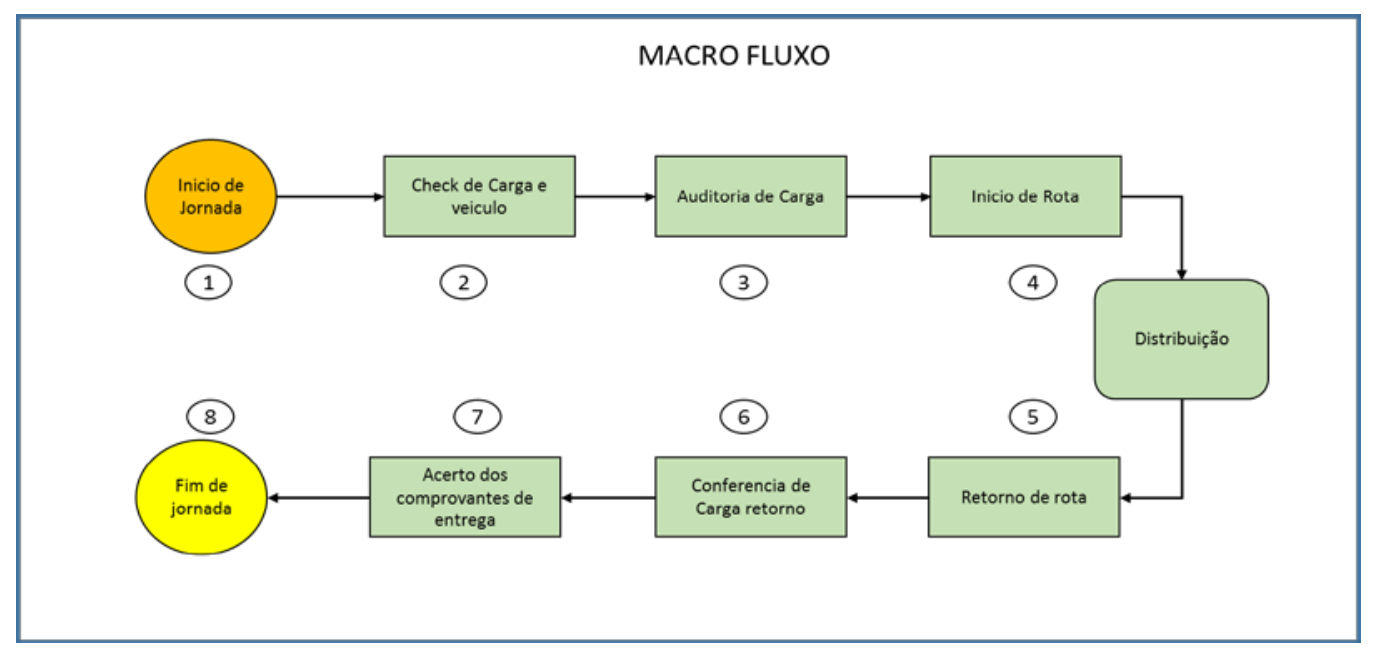

Figura 15 - Macro fluxo referente ao processo interno de pátio.

Fonte: Autor (2017).

Ao analisar a figura 15, observa-se que o marco fluxo divide a operação de pátio em 7 momentos:

- $\mathbf{1}^{\mathbf{0}}$ Momento - Início de Jornada: caracterizado pela chegada do motorista ao centro de distribuição e registro do seu ponto, para início de sua jornada de trabalho.

- $2^{\mathbf{o}}$ Momento - Check de Documentação de carga e veículo: momento em que a tripulação se desloca até seu veículo, munido do mapa de carga do dia e realiza a conferência da carga. Neste mesmo momento, realiza o check list sobre as condições básicas de mecânica do veículo.

- $3^{\circ}$ Momento - Auditoria de Carga: nesta etapa, alguns veículos são selecionados, aleatoriamente, para uma auditoria de carga a ser realizada pelo conferente. 
-4 $4^{\mathbf{0}}$ Momento - Início de Rota: nesta etapa, a tripulação se apresenta com o veículo junto à portaria e realiza seu registro de saída e finaliza sua rotina interna, dando início ao roteiro de entrega planejado.

- $5^{\circ}$ Momento - Retorno de Rota: tripulação registra seu retorno de rota e finaliza sua atividade de entrega e inicia o processo interno de descarga e prestação de contas referente às entregas realizadas.

- $6^{0}$ Momento - Conferência de carga retorno: a tripulação se desloca com o veículo para doca de conferência, o conferente realiza o check das atividades de: conferência da devolução, vasilhame, recolhas e avarias de produtos.

- $7^{0}$ Momento - Acerto dos comprovantes de entrega: finalizando a atividade de conferência, a tripulação se desloca ao setor de acerto, e realiza a prestação de contas, como: numerário recebido, canhoto de NFe e boleto.

- $8^{\mathbf{o}}$ Momento - Término de Jornada: tripulação realiza o fechamento do seu ponto, e finaliza sua jornada de trabalho.

\subsection{1}

\section{Entendimento do comportamento da operação}

Antes de iniciar a atividade de simulação ou aplicar qualquer alteração no modelo atual da operação do pátio, é necessário realizar o entendimento do seu comportamento. Este entendimento só é possível através da atividade de coleta de dados inerentes a operação.

Para esta pesquisa-ação, a atividade da coleta de dados, dividiu-se em dois momentos. No primeiro momento realizou-se o mapeamento e levantamento dos dados e na sequência a análise dos dados, que serão melhor apresentados nos capítulos 5.2.1.1 - Coleta de dados e 5.2.1.2 - Análise dos dados.

\subsubsection{1}

\section{Coleta de dados}

Para desenvolvimento do estudo da operação de pátio foi realizado a coleta de dados de forma contínua, ou seja, quando os eventos que acontecem durante o estudo, são registradas as medidas que ocorrem. 
Para esta atividade foi utilizado o software de captura de dados, conforme demostrado no capítulo 4.3 - GreenMile, capaz de acompanhar a rotina da operação conforme seu acontecimento e monitorar todas as ações no qual foram definidas.

O software instalado no celular possibilita a tripulação informar seu status a cada evento, desde sua entrada no CD ao posicionar o início de sua jornada, até sua saída, ao posicionar seu término de jornada, conforme demostrado na figura 16.

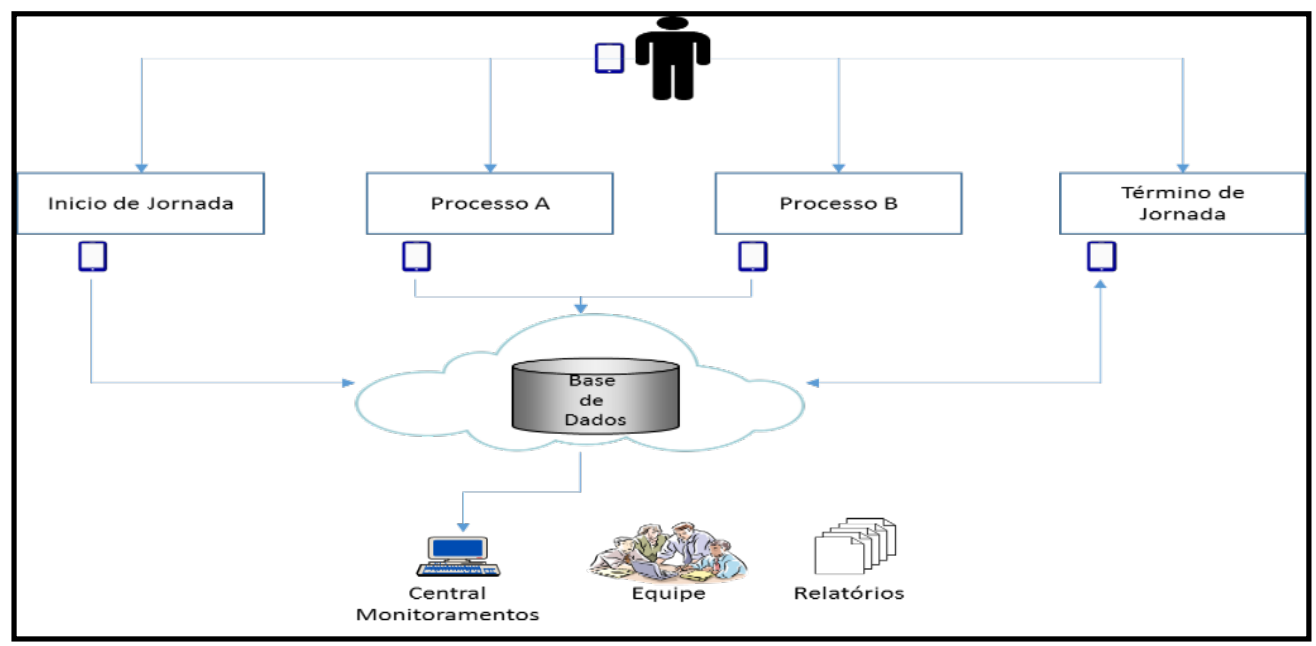

Figura 16 - Monitoramento das atividades de pátio.

Fonte: Autor (2017).

Ao utilizar este software, foram coletados dados como:

- Registro de início de jornada

- Registro do início de conferência de carga para saída

- Registro do início da auditoria de carga (antes de sua saída)

- Registro de portaria (saída para rota de entrega)

- Registro de portaria (retorno da rota de entrega)

- Registro de início de conferência de carga retorno

- Registro do fechamento de acerto de entrega

- Registro de término de jornada

Outro fator importante levantado, foi o quadro de funcionários e a relação de ativos, veículos, utilizados na operação. 
Com a base de dados gerada, a equipe iniciou o trabalho de análise de dados, conforme capitulo 5.2.1.2 - Análise dos dados.

Vale ressaltar que foram utilizados dados coletados entre o período 01/01/2014 a 31/08/2014.

\subsubsection{2}

\section{Análise dos dados}

Nesta etapa, analisa-se os dados coletados na operação para realizar o entendimento da movimentação interna ocorrida no pátio e identificar o tempo e ritmo de funcionamento de cada atividade, com objetivo de identificar a função de distribuição que melhor se adaptava ao processo e aplicar a informação ao modelo criado no simulador Arena. Para esta análise, aplica-se a ferramenta input Analayzer, disponível no próprio software Arena, onde o mesmo aponta em suas simulação diversas funções compatíveis aos dados analisados, no qual está determinado a aplicar a melhor alternativa sugerida pela ferramenta, sendo possível validar a melhor curva de distribuição de probabilidade das atividades, conforme mostra o Quadro 3 - Curva de distribuição de probabilidade das atividades.

Quadro 3 - Curva de distribuição de probabilidade das atividades.

\begin{tabular}{|l|l|l|}
\hline \multicolumn{1}{|c|}{ Processo } & \multicolumn{1}{c|}{ Distribuição } & \multicolumn{1}{c|}{ Expressão } \\
\hline Início de jornada & Exponencial & $60+\operatorname{EXPO}(116)$ \\
\hline $\begin{array}{l}\text { Check de documentação } \\
\text { de carga e veiculo }\end{array}$ & Lognormal & $-0.5+\operatorname{LOGN}(9.26,4.15)$ \\
\hline Auditoria de Carga & Exponencial & $550+\operatorname{EXPO}(562)$ \\
\hline Retorno de Rota & Gama & $10+\operatorname{GAMM}(958,0.505)$ \\
\hline $\begin{array}{l}\text { Conferência de Carga } \\
\text { retorno }\end{array}$ & Exponencial & $120+\operatorname{EXPO}(480)$ \\
\hline $\begin{array}{l}\text { Acerto dos Comprovantes } \\
\text { de entrega }\end{array}$ & Gama & $96+\operatorname{GAMM}(106,0.892)$ \\
\hline
\end{tabular}

Estas foram as curvas de distribuição de probabilidade das atividades simuladas aplicadas ao cenário atual e futuro a ser apresentado no nos capítulos 5.3 - Cenário atual e 5.4 - Cenário Futuro. 


\section{3}

\section{Cenário Atual}

Para construção do cenário atual no Arena, foi aplicado o macro fluxo do processo conforme apresentando no capitulo 5.2 - Mapeamento de fluxo do processo de movimentação interna. O resultado está ilustrado na figura 17.

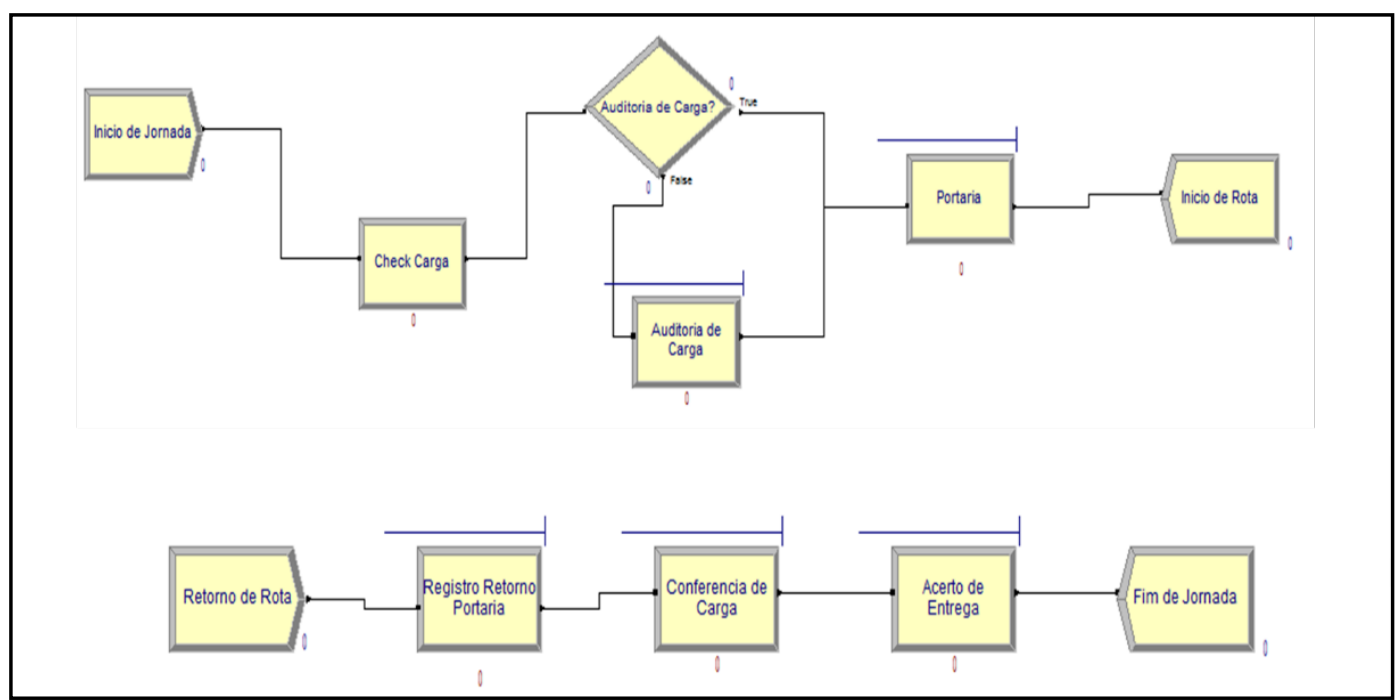

Figura 17 - Modelo para análise do fluxo de pátio, cenário atual, construído no Arena. Fonte: Arena.

Como input de informações para simulação, foram utilizados dados operacionais levantados conforme apresentado no quadro 4.

Quadro 4 - Dados para input e simulação do cenário futuro.

\section{Objetos}

Jornada de Trabalho

Qtd. De Veículos

Qtd. De Motoristas

Qtd. De Conferente

Qtd. De Atendentes

Qtd. De Porteiros

Qtd. De Ajudantes de Entrega

Auditoria de Carga

\section{Premissas}

10

43

43

01

01

01

68

40\% dos veículos auditados
Obs.:

Horas diárias

Conferências de carga

Acerto de entrega

Métrica é de 1,6 ajudantes por motorista 
Após parametrização do modelo, foram realizadas 30 replicações, com objetivo de testar o modelo no período de 1 mês, na sequência, o report analyzer apresentou, por processo, os possíveis gargalos bem como taxa de utilização dos recursos alocadas em cada etapa. O resultado poderá ser analisado no capitulo 5.3.1 Resultado simulação arena (cenário atual).

\subsection{1}

\section{Resultado Simulação Arena (Cenário Atual)}

Para análise dos resultados, dividiu-se o modelo nas 2 principais variáveis, ou seja: $T P_{0}$-Tempo de Pátio Inicial e $T P_{f}$ Tempo de Pátio Final.

- $\boldsymbol{T} \boldsymbol{P}_{\mathbf{0}}$ Tempo de Pátio Inicial: Como pode ser observado no quadro 5, o processo de auditoria de carga, possui um tempo médio de fila, Average, de 6115.45 segundos, ou seja, 1:41:55 horas, sendo o maior ofensor dentro do processo de liberação de carga, onde se faz necessário auditar $40 \%$ dos veículos a serem expedidos para distribuição.

Mesmo com o tempo de fila gerado no processo de auditoria de carga, o recurso alocado no processo, está com 58,07\% de ocupação, conforme pode ser analisado no quadro 6 , que pode ser justificado pela concentração da atividade de auditoria estar toda no início do processo

Quadro 5 - Resultado simulação cenário atual: Tempo de fila dos processos $\mathbf{T} \boldsymbol{P}_{\mathbf{0}}$.

\begin{tabular}{|l|c|c|c|c|}
\hline Waiting Time & Average & Half Widht & $\begin{array}{c}\text { Minimun } \\
\text { Average }\end{array}$ & $\begin{array}{c}\text { Maximum } \\
\text { Average }\end{array}$ \\
\hline $\begin{array}{l}\text { Auditoria de } \\
\text { Carga. Queue }\end{array}$ & 6115.45 & $1.067,02$ & 2214.05 & 12731.94 \\
\hline $\begin{array}{l}\text { Portaria. } \\
\text { Queue }\end{array}$ & 0.5087 & 0,19 & 0.00 & 1.9052 \\
\hline
\end{tabular}

$\boldsymbol{T} \boldsymbol{P}_{\mathbf{0}}$ Fonte: Arena.

Quadro 6 - Resultado simulação cenário atual: Taxa de utilização dos recursos aplicados $\boldsymbol{T} \boldsymbol{P}_{\mathbf{0}}$,

\begin{tabular}{|l|c|c|c|c|}
\hline \multicolumn{1}{|c|}{ Waiting Time } & Average & Half Widht & $\begin{array}{c}\text { Minimun } \\
\text { Average }\end{array}$ & $\begin{array}{c}\text { Maximum } \\
\text { Average }\end{array}$ \\
\hline R_Conferente_S & 0.5807 & 0.06 & 0.3388 & 0.8920 \\
\hline R_Porteiro_S & 0.03583333 & 0.00 & 0.03583333 & 0.03583333 \\
\hline
\end{tabular}

$\boldsymbol{T} \boldsymbol{P}_{\mathbf{0}}$ Fonte: Arena. 
- $\boldsymbol{T} \boldsymbol{P}_{\boldsymbol{f}}$ Tempo de Pátio Final: Conforme pode ser observado no quadro 7, ao término da simulação do atual cenário, o ciclo de processos avaliados no $T P_{f}$ apontam que o processo de conferência de carga no retorno é o maior ofensor, gerando um tempo médio de fila, average, com total de 3759,43 segundos, ou seja, 01:02:39 horas para execução, os demais processos não apontam um gargalo durante sua execução. Ao analisar o quadro 8 observa-se que o uso do recurso alocado para esta atividade chega a 74,20\% de ocupação do seu trabalho, mesmo sendo um percentual maior do que o verificado no processo de auditoria de carga durante a análise do $T P_{0}$, pode-se afirmar que operacionalmente é uma taxa de ocupação de recurso dentro do nível aceitável.

Quadro 7 - Resultado simulação cenário atual: Tempo de fila dos processos $\boldsymbol{T P}_{\boldsymbol{f}}$.

\begin{tabular}{|c|c|c|c|c|}
\hline Waiting Time & Average & Half Widht & $\begin{array}{l}\text { Minimun } \\
\text { Average }\end{array}$ & $\begin{array}{c}\text { Maximum } \\
\text { Average }\end{array}$ \\
\hline $\begin{array}{l}\text { Acerto de } \\
\text { entrega. Queue }\end{array}$ & 18,4357 & 4,62 & 3,3700 & 51,5334 \\
\hline $\begin{array}{l}\text { Conferência de } \\
\text { carga. Queue }\end{array}$ & 3759,43 & 960,58 & 693,27 & 9844,96 \\
\hline Portaria. Queue & 1,4939 & 0,26 & 0,2757 & 3,0216 \\
\hline
\end{tabular}

$\boldsymbol{T P}_{f}$ Fonte: Arena.

Quadro 8 - Resultado simulação cenário atual: Taxa de utilização dos recursos aplicados $\boldsymbol{T} \boldsymbol{P}_{f}$.

\begin{tabular}{l|c|c|c|c|}
\hline \multicolumn{1}{|c|}{ Waiting Time } & Average & Half Widht & $\begin{array}{c}\text { Minimun } \\
\text { Average }\end{array}$ & $\begin{array}{c}\text { Maximum } \\
\text { Average }\end{array}$ \\
\hline $\begin{array}{l}\text { R_Assistente } \\
\text { Financeiro }\end{array}$ & 0,2278 & 0,01 & 0,1973 & 0,2540 \\
\hline R_Conferente_S & 0,7420 & 0,04 & 0,5694 & 0,9374 \\
\hline R_Porteiro_S & 0,03580556 & 0,00 & 0,03500000 & 0,03583333 \\
\hline
\end{tabular}

Ao analisar todo o processo, ou seja, $\boldsymbol{T} \boldsymbol{P}_{\mathbf{0}}+\boldsymbol{T} \boldsymbol{P}_{\boldsymbol{f}}$, determina-se o tempo gasto nas atividades de pátio realizada pela tripulação (Motoristas e ajudantes de entrega).

Assim sendo, conforme apresentado no quadro 9, temos o tempo livre para atividade de distribuição e que poderá ser utilizada como parâmetro a ser aplicado no software roadnet, podendo desta forma realizar a roteirização e 
consequentemente o dimensionamento de frota necessárias para atendimento da quantidade de entregas da demanda de acordo com o dia.

Quadro 9 - Resultado simulado no cenário atual para tempo de Jornada.

\begin{tabular}{|c|c|c|}
\hline Variáveis & Tempo & Observação \\
\hline$T P_{0}$ & $1: 42: 25$ & $\begin{array}{l}\text { Tempo aplicado aos } \\
\text { processos } \\
\text { administrativos } \\
\text { realizados pela } \\
\text { tripulação antes de sua } \\
\text { saída para rota }\end{array}$ \\
\hline $\begin{array}{c}D I_{1}+\sum_{i \in I} T E_{i}+\sum_{\substack{i \in I \\
+D F_{N}}}^{N-1} \sum_{j \in I=i+1}^{N} D P_{i j} \\
\end{array}$ & 7:13:09 & $\begin{array}{l}\text { Tempo disponível para } \\
\text { roteirização de entrega. }\end{array}$ \\
\hline $\boldsymbol{T P} \boldsymbol{P}_{f}$ & 01:04:26 & $\begin{array}{l}\text { Tempo aplicado aos } \\
\text { processos } \\
\text { administrativos } \\
\text { realizados pela } \\
\text { tripulação no retorno de } \\
\text { rota }\end{array}$ \\
\hline$T J$ & 10:00:00 & $\begin{array}{l}\text { Tempo total de jornada } \\
\text { de trabalho permitida } \\
\text { pela CLT. }\end{array}$ \\
\hline
\end{tabular}

A simulação do cenário atual aponta gargalo em 2 processos dentro das atividades de $\boldsymbol{T} \boldsymbol{P}_{\mathbf{0}}$ e $\boldsymbol{T} \boldsymbol{P}_{\boldsymbol{f}}$, no qual precisa ser trabalhada pela equipe de pesquisa, com objetivo de minimizar o tempo de pátio, maximizando o tempo para o processo de roteirização das entregas, possibilitando o aumento de quantidade de entregas nos veículos.

\section{4}

\section{Cenário Futuro}

Com o objetivo de minimizar o tempo de pátio, foram realizadas alterações no processo e no quadro de recursos.

- Quanto ao processo: neste caso fica definido que será alterado a escala de trabalho da equipe de entrega, sendo dividida em 3 janelas de entrada, com intervalos de 00:40:00 minutos entre cada janela. Com objetivo de reduzir o fluxo na entrada da equipe, para melhoria da gestão e agilidade nos processos. 
- Quanto ao quadro de recurso: neste caso analisa-se a necessidade de aumentar 1 conferente, com objetivo de agilizar os processos de auditoria de carga e conferência de carga no retorno. Pode-se observar esta alteração no quadro 10 de inputs operacionais utilizado para parametrização do cenário futuro no simulador Arena.

Quadro 10 - Dados para input e simulação do cenário futuro.

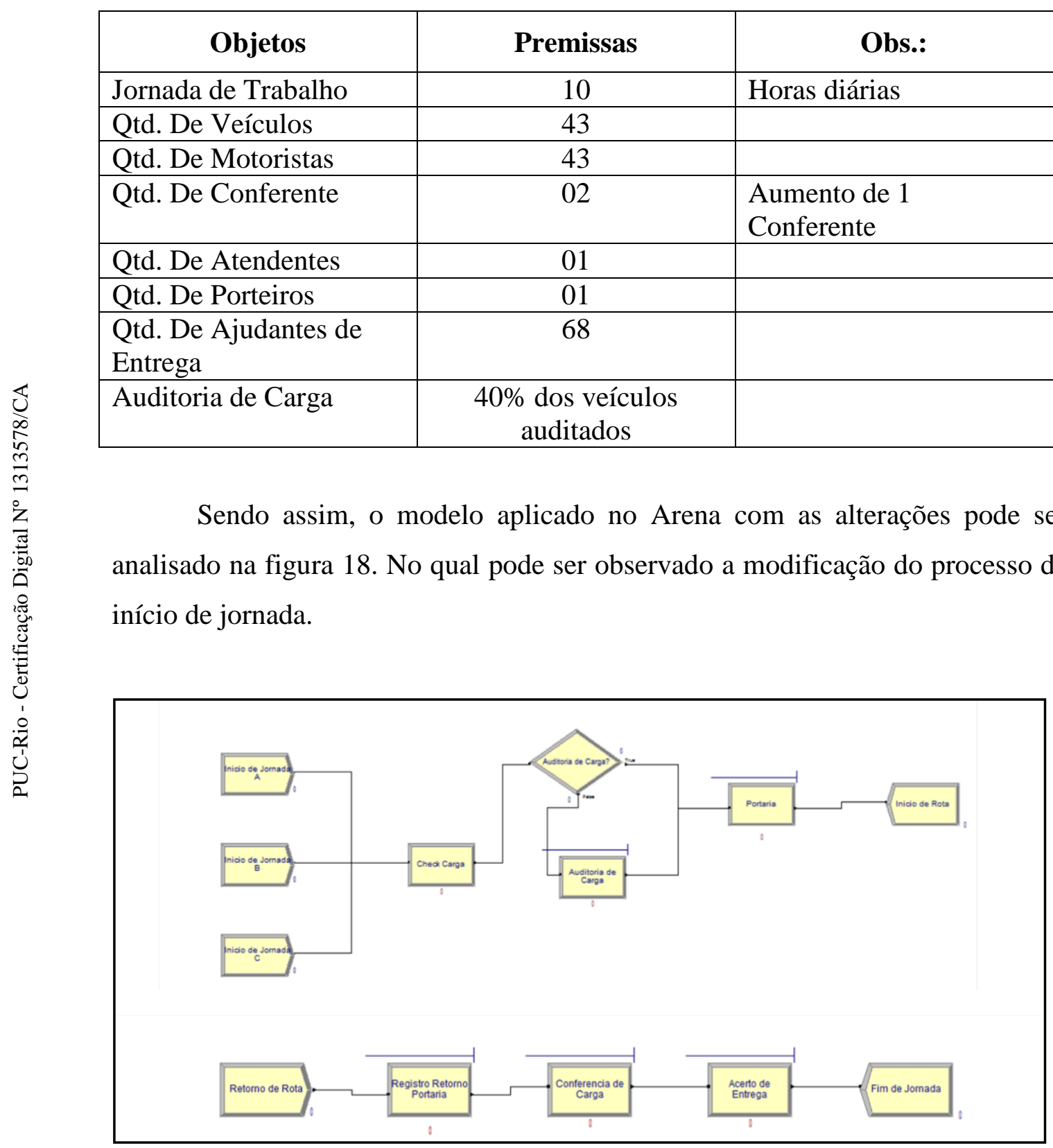

Figura 18 - Modelo para análise do fluxo de pátio, cenário futuro, construído no Arena. Fonte: Arena. 
Após parametrização do modelo, foram realizadas 30 replicações, com objetivo de testar o modelo no período de 1 mês, na sequência, o report analyzer apresentou, por processo, os possíveis gargalos bem como taxa de utilização dos recursos alocadas em cada etapa. O resultado poderá ser analisado no capítulo 5.4.1 Resultado simulação arena (cenário futuro).

\subsection{1}

\section{Resultado Simulação Arena (Cenário Futuro)}

Seguindo o mesmo modelo de análise aplicado no capitulo 5.3.1- Cenário Atual. Divide-se o modelo nas 2 principais variáveis, ou seja: $T P_{0}-$ Tempo de Pátio Inicial e $T P_{f}$ Tempo de Pátio Final.

- $\boldsymbol{T} \boldsymbol{P}_{0}$ Tempo de Pátio Inicial: na simulação do cenário futuro, pode ser observado no quadro 11 que o processo de auditoria de carga, agora possui um tempo de fila médio, average, de 1381,33 segundos, ou seja, 0:23:01 minutos, sendo ainda o maior ofensor dentro do processo de liberação de carga.

Mesmo com o tempo de fila gerado no processo de auditoria de carga, os recursos alocados neste processo, estão com 27,92\% de ocupação, conforme pode ser analisado no quadro 12.

Quadro 11 - Resultado simulação do cenário futuro: Tempo de fila dos processos $\boldsymbol{T P}_{\mathbf{0}}$.

\begin{tabular}{|l|c|c|c|c|}
\hline Waiting Time & Average & Half Widht & $\begin{array}{c}\text { Minimun } \\
\text { Average }\end{array}$ & $\begin{array}{c}\text { Maximum } \\
\text { Average }\end{array}$ \\
\hline $\begin{array}{l}\text { Auditoria de } \\
\text { Carga. Queue }\end{array}$ & 1381,33 & 289,88 & 193,16 & 3701,62 \\
\hline $\begin{array}{l}\text { Portaria. } \\
\text { Queue }\end{array}$ & 1,1291 & 0,29 & 0,00 & 3,1015 \\
\hline
\end{tabular}

$\boldsymbol{T P}_{\mathbf{0}}$ Fonte: Arena.

Quadro 12 - Resultado simulação cenário futuro: Taxa de utilização dos recursos aplicados $\boldsymbol{T} \boldsymbol{P}_{\mathbf{0}}$.

\begin{tabular}{|l|c|c|c|c|}
\hline \multicolumn{1}{|c|}{ Waiting Time } & Average & Half Widht & $\begin{array}{c}\text { Minimun } \\
\text { Average }\end{array}$ & $\begin{array}{c}\text { Maximum } \\
\text { Average }\end{array}$ \\
\hline R_Conferente_S & 0,2792 & 0,02 & 0,1746 & 0,4225 \\
\hline R_Porteiro_S & 0,03583333 & 0,00 & 0,03583333 & 0,03583333 \\
\hline
\end{tabular}


- $\boldsymbol{T} \boldsymbol{P}_{\boldsymbol{f}}$ Tempo de Pátio Final: Conforme pode ser observado no quadro 13, ao término da simulação do cenário futuro, o ciclo de processos avaliados no $T P_{f}$ apontam que o processo de conferência de carga no retorno ainda como o maior ofensor, gerando um tempo medido de fila, average, no total de 404,33 segundos, ou seja, 00:06:36 minutos para execução. Ao analisar o quadro 14 observa-se que o uso do recurso alocado para esta atividade chega a 36,43\% de carga do seu trabalho.

Quadro 13 - Resultado simulação cenário atual: Tempo de fila dos processos $\boldsymbol{T P}_{\boldsymbol{f}}$.

\begin{tabular}{|l|c|c|c|c|}
\hline \multicolumn{1}{|c|}{ Waiting Time } & Average & Half Widht & $\begin{array}{c}\text { Minimun } \\
\text { Average }\end{array}$ & $\begin{array}{c}\text { Maximum } \\
\text { Average }\end{array}$ \\
\hline $\begin{array}{l}\text { Acerto de } \\
\text { entrega. Queue }\end{array}$ & 61,4507 & 14,19 & 19,3257 & 168,25 \\
\hline $\begin{array}{l}\text { Conferência de } \\
\text { carga. Queue }\end{array}$ & 404,33 & 106,75 & 59,4921 & 1440,78 \\
\hline Portaria. Queue & 1,5366 & 0,26 & 0,07136623 & 2,9239 \\
\hline
\end{tabular}

$\boldsymbol{T P}_{f}$ Fonte: Arena.

Quadro 14 - Resultado simulação cenário atual: Taxa de utilização dos recursos aplicados $\boldsymbol{T} \boldsymbol{P}_{f}$.

\begin{tabular}{|l|c|c|c|c|}
\hline \multicolumn{1}{|c|}{ Waiting Time } & Average & Half Widht & $\begin{array}{c}\text { Minimun } \\
\text { Average }\end{array}$ & $\begin{array}{c}\text { Maximum } \\
\text { Average }\end{array}$ \\
\hline $\begin{array}{l}\text { R_Assistente } \\
\text { Financeiro }\end{array}$ & 0,2252 & 0,01 & 0,1867 & 0,2695 \\
\hline R_Conferente_S & 2,3643 & 0,01 & 0,2799 & 0,4533 \\
\hline R_Porteiro_S & 0,03583333 & 0,00 & 0,03583333 & 0,03583333 \\
\hline
\end{tabular}

$\boldsymbol{T P}_{\boldsymbol{f}}$ Fonte: Arena

Ao analisar todo o resultado do processo, ou seja, $\boldsymbol{T} \boldsymbol{P}_{\mathbf{0}}+\boldsymbol{T} \boldsymbol{P}_{\boldsymbol{f}}$, determina-se o tempo gasto nas atividades de pátio realizada pela tripulação (Motoristas e ajudantes de entrega).

Assim sendo, conforme apresentado no quadro 15, temos o tempo livre para atividade de distribuição e que poderá ser utilizada como parâmetro a ser aplicado no software roadnet, podendo desta forma realizar a roteirização e consequentemente o dimensionamento de frota necessárias para atendimento da quantidade de entregas da demanda de acordo com o dia. 
Quadro 15 - Resultado simulado no cenário futuro para tempo de Jornada.

\begin{tabular}{|c|c|c|}
\hline Variáveis & Tempo & Observação \\
\hline$T P_{0}$ & 0:23:31 & $\begin{array}{lr}\text { Tempo } & \text { aplicado aos } \\
\text { processos } & \text { administrativos } \\
\text { realizados } & \text { pela tripulação } \\
\text { antes de sua saída para rota }\end{array}$ \\
\hline $\begin{array}{c}D I_{1}+\sum_{i \in I} T E_{i}+\sum_{\substack{i \in I \\
+D F_{N}}}^{N-1} \sum_{j \in I=i+1}^{N} D P_{i j} \\
\end{array}$ & 09:28:24 & $\begin{array}{l}\text { Tempo disponível para } \\
\text { roteirização de entrega. }\end{array}$ \\
\hline$T P_{f}$ & 00:08:05 & $\begin{array}{l}\text { Tempo aplicado aos } \\
\text { processos administrativos } \\
\text { realizados pela tripulação no } \\
\text { retorno de rota }\end{array}$ \\
\hline$T J$ & 10:00:00 & $\begin{array}{l}\text { Tempo total de jornada de } \\
\text { trabalho permitida pela CLT. }\end{array}$ \\
\hline
\end{tabular}

\section{5}

\section{Resultados}

Ao comprar os resultados, obtidos na simulação, entre o cenário atual e futuro observa-se que as mudanças sugeridas trazem resultados significativos que podem agilizar nos processos de liberação e retorno dos veículos, disponibilizando mais tempo para atividade de distribuição. O resultado pode ser melhor comparado através do quadro 16 - comparação dos resultados simulados pelo Arena, aonde se verifica o potencial ganho.

Quadro 16 - comparação dos resultados simulados pelo Arena.

\begin{tabular}{|c|c|c|c|}
\hline Variáveis & $\begin{array}{c}\text { Tempo } \\
\text { Cenário } \\
\text { Atual }\end{array}$ & $\begin{array}{c}\text { Tempo } \\
\text { Cenário } \\
\text { Futuro }\end{array}$ & Melhoria \\
\hline $\boldsymbol{T} \boldsymbol{P}_{\mathbf{0}}$ & $01: 42: 25$ & $00: 23: 31$ & $(01: 18: 54)$ \\
\hline $\boldsymbol{D} \boldsymbol{I}_{\mathbf{1}}+\sum_{\boldsymbol{i} \in \boldsymbol{I}} \boldsymbol{T} \boldsymbol{E}_{\boldsymbol{i}}+\sum_{\boldsymbol{i} \in \boldsymbol{I}}^{N-1} \sum_{\boldsymbol{j} \in \mathbf{I} \boldsymbol{j}=\boldsymbol{i}+\mathbf{1}}^{N} \boldsymbol{D} \boldsymbol{P}_{\boldsymbol{i} \boldsymbol{j}}$ & $07: 13: 19$ & $09: 28: 24$ & $02: 15: 15$ \\
\hline $\boldsymbol{T} \boldsymbol{P}_{\boldsymbol{f}}$ & $01: 04: 26$ & $00: 08: 05$ & $(0: 56: 21)$ \\
\hline $\boldsymbol{T J}$ & $10: 00: 00$ & $10: 00: 00$ & \\
\hline
\end{tabular}

Fonte: Arena. 
Ao comprar o cenário atual e futuro, nota-se que as alterações sugeridas apresentam uma redução no tempo de permanências dos veículos no pátio, conseguindo alcançar uma redução de 2:15:15 horas no total. No processo inicial $\boldsymbol{T} \boldsymbol{P}_{\mathbf{0}}$. A modificação, incluindo 1 conferente, agilizou o processo de auditoria de carga no qual apresenta um ganho de 1:18:54 horas, já no processo final, $\boldsymbol{T} \boldsymbol{P}_{\boldsymbol{f}}$, a inclusão do conferente também auxiliou, porém, o fato de ter alterado a escala de entrada da tripulação, divididas em grupos com intervalo de 00:40:00 minutos entre cada grupo, reduziu a concentração no retorno dos veículos, este foi o grande fator para o ganho de 00:56:21 minutos.

O Processo de implementação da alteração do modelo e operação foi realizado de forma direta, ou seja, inclusão de 1 conferente e alteração da escala dos recursos.

O processo para parametrização do roteirizador, foi realizado de forma mais analítica, ou seja, o parâmetro de horas máximas a ser utilizada para criação de um roteiro, foi alterada para 09:28:00 horas, porém, o incremento de quantidade de entregas por veículo, foi realizado de forma escalonada. Esta estratégia foi definida pela equipe de projeto, com objetivo de alterar a rotina e volume de trabalho dos motoristas de forma evolutiva, buscando adaptação para o novo volume de trabalho.

Durante a mudança de processo alguns indicadores, conforme figura 19, foram acompanhados com objetivo de validar as variáveis alteradas. Em particular 3 indicadores sinalizados como principais foram acompanhados de perto: Dispersão (km/entrega), Devolução e Estouro de jornadas. 


\begin{tabular}{|c|c|c|c|c|c|c|c|c|c|c|c|c|}
\hline \multirow[b]{2}{*}{ Ano } & \multirow[b]{2}{*}{ Mês } & \multirow[b]{2}{*}{$\begin{array}{l}\text { Media de } \\
\text { entrega }\end{array}$} & \multirow[b]{2}{*}{$\begin{array}{c}\text { Qtd. } \\
\text { Entregas }\end{array}$} & \multirow[b]{2}{*}{$\begin{array}{l}\text { Qtd. Clientes } \\
\text { Atendidos }\end{array}$} & \multirow[b]{2}{*}{$\begin{array}{c}\text { Dispersão } \\
\text { (KM/Entrega) - } \\
\text { Frota Própria }\end{array}$} & \multirow[b]{2}{*}{$\begin{array}{c}\text { Km Real x } \\
\text { Planejado (\%) - } \\
\text { Frota Própria }\end{array}$} & \multirow[b]{2}{*}{ Spot } & \multirow[b]{2}{*}{ Devolução } & \multicolumn{3}{|c|}{ Veiculos Utilizados } & \multirow[b]{2}{*}{$\begin{array}{l}\text { Estouro de } \\
\text { Jornada }\end{array}$} \\
\hline & & & & & & & & & Minimo & Media & Maxima & \\
\hline \multirow{12}{*}{$\underset{\mathbf{V}}{\mathbf{D}}$} & $\operatorname{Jan}$ & 24 & 21.774 & 9.044 & 2,75 & $5,62 \%$ & 50 & $0,87 \%$ & 27 & 40 & 43 & 79 \\
\hline & Fev & 25 & 21.455 & 9.209 & 2,67 & $5,10 \%$ & 59 & $0,75 \%$ & 37 & 42 & 43 & 64 \\
\hline & Mar & 25 & 21.664 & 9.276 & 2,70 & $9,72 \%$ & 44 & $0,99 \%$ & 38 & 41 & 43 & 42 \\
\hline & Abr & 26 & 22.338 & 9.238 & 2,72 & $7,69 \%$ & 36 & $1,30 \%$ & 27 & 39 & 43 & 33 \\
\hline & Mai & 27 & 24.406 & 9.405 & 2,59 & $6,65 \%$ & 21 & $1,11 \%$ & 35 & 41 & 43 & 37 \\
\hline & Jun & 28 & 22.338 & 9.450 & 2,58 & $7,99 \%$ & 32 & $1,29 \%$ & 34 & 40 & 43 & 52 \\
\hline & Jul & 26 & 23.727 & 9.537 & 2,62 & $8,41 \%$ & 7 & $1,10 \%$ & 31 & 38 & 41 & 32 \\
\hline & Ago & 29 & 24.765 & 9.626 & 2,46 & $8,85 \%$ & 28 & $0,72 \%$ & 28 & 36 & 39 & 62 \\
\hline & Set & 28 & 23.214 & 9.154 & 2,55 & $6,51 \%$ & 26 & $0,77 \%$ & 29 & 36 & 39 & 56 \\
\hline & Out & 28 & 22.550 & 9.118 & 2,57 & $7,54 \%$ & 51 & $1,52 \%$ & 24 & 33 & 37 & 93 \\
\hline & Nov & 28 & 22.714 & 9.749 & 2,45 & $7,60 \%$ & 15 & $1,50 \%$ & 34 & 37 & 40 & 17 \\
\hline & Dez & 29 & 23.224 & 9.890 & 2,35 & $6,41 \%$ & 38 & $1,68 \%$ & 22 & 34 & 39 & 44 \\
\hline \multirow{6}{*}{$\stackrel{0}{0}$} & Jan & 31 & 21.661 & 10.278 & 2,26 & $12,75 \%$ & 30 & $0,99 \%$ & 17 & 32 & 35 & 29 \\
\hline & Fev & 32 & 19.167 & 9.826 & 2,24 & $8,99 \%$ & 24 & $1,55 \%$ & 27 & 32 & 35 & 31 \\
\hline & Mar & 32 & 18.805 & 8.525 & 2,42 & $0,36 \%$ & 0 & $1,75 \%$ & 23 & 28 & 33 & 18 \\
\hline & Abr & 32 & 18.422 & 8.121 & 2,39 & $3,27 \%$ & 28 & $2,23 \%$ & 24 & 29 & 33 & 22 \\
\hline & Mai & 33 & 18.936 & 8.634 & 2,21 & $1,88 \%$ & 23 & $1,29 \%$ & 24 & 28 & 30 & 25 \\
\hline & Jun & 30 & 17.718 & 8.652 & 2,30 & $7,00 \%$ & 20 & $2,08 \%$ & 19 & 28 & 30 & 21 \\
\hline
\end{tabular}

Figura 19 - Mapa do acompanhamento de indicadores.

Fonte: Base de dados sistema TMS-SAP.

- Dispersão (Km/entregas): o indicador mede a dispersão entre os pontos de entregas definidos pelo roteirizador. Neste indicador, tivemos melhoria quanto à dispersão. O fato de aumentar a quantidade de entregas por veículos, possibilita a concentração de entrega na mesmo raio de região, melhorando o indicador.

- Devolução: o indicador mede a quantidade de NFe devolvidas, a medição ocorre sobre valor da NFe. A preocupação neste caso, era a possibilidade de piora devido ao não cumprimento da entrega pelo fato de estouro de jornada, aquela que ocorre quando o motorista não conclui a rota e alega que a jornada “tempo” disponível não seria o suficiente para realização das entregas. Este fator não ocorreu e o indicador continuou estável, acredita-se que pela melhoria do indicador de dispersão, os pontos de entregas ficaram mais próximos e facilitou a execução do serviço.

- Estouro de Jornada: um dos indicadores de maior preocupação, pois a alteração deixa a equipe de entrega ainda mais tempo exposto a variáveis externas (congestionamentos, acidentes, etc..) e não controláveis. Como observado, o indicador também não sofreu alterações, todos os estouros de jornadas ocorridos foram justificados devido a problemas inerentes ao trânsito.

A manutenção dos indicadores, mesmo após alteração no modelo, validou o novo cenário e junto trouxe ganhos financeiros. 
Os principais ganhos foram quanto à redução de km percorridos durante a execução de entrega, onde o novo modelo conseguiu agregar eficiência no km total a ser percorrido, no qual economizou $49.894 \mathrm{~km}$ percorridos ano o que representa um total de 13.437 litros de combustível. Outra grande economia foi na redução de equipamentos necessários para operação, no qual foram reduzidos 8 veículos de entrega e consequentemente 24 pessoas entre motoristas e ajudantes.

No período de 12 meses, apurou-se a economia total de $\mathrm{R} \$ 685.234,00$ vinculados principalmente a redução de despesas operacionais como: manutenção dos veículos, salário (motoristas e ajudantes), pneus, combustível, seguro dos veículos e depreciação dos veículos. Não levando em consideração o custo de venda dos equipamentos que foram disponibilizados a outras filiais do grupo pertencente a empresa BETA. 


\section{Conclusão}

Pode-se concluir que ao se pensar em gestão de distribuição, devemos focar nas restrições da tripulação (motoristas e ajudantes) e não somente nas dos roteiros e clientes, sendo necessário conhecer todas as variáveis de tempo do sistema de distribuição. Onde uma variável de tempo desprezada, como a do tempo de pátio, pode significar muito em termos de produtividade no processo de entrega. Este estudo mostra que o tempo de pátio não pode ser desprezado, pois assume um papel preponderante para uma maior produtividade das operações de distribuição.

Outro ponto importante a se observar é que realizar a extensão do tempo de ciclo para o tempo de jornada, incluir variáveis de $\boldsymbol{T} \boldsymbol{P}_{\mathbf{0}}+\boldsymbol{T} \boldsymbol{P}_{\boldsymbol{f}}$, pode ser aplicado ao qualquer modelo de VRP apresentando nesta pesquisa, com intuito de agregar gestão na de jornada de trabalho da tripulação embarcada, fazendo assim estabelecer controle para cumprir com as exigências da CLT, principalmente após aplicação da lei No 12.619.

Ao analisar o mapa de indicadores figura 19, observa-se o ganho com o aumento de produtividade na média de entregas por veículo, que afeta diretamente na redução da frota e na dispersão entre pontos de entrega, mostrando que a consolidação traz também o benefício a eficiência de roteiro, fazendo com que a frota percorra um menor quilómetro com o mesmo perfil de atendimento a clientes.

Nota-se que os indicadores de contratação de veículos spot “terceiros” não se alteraram, o que provavelmente se deve à necessidade de entregas fora do perfil fracionado.

O indicador de devolução manteve-se estável, mostrando que o novo modelo não impactou em ineficiência de atendimento.

O indicador de estouro de jornada, demostra que o modelo ainda não consegue eliminar todos os possíveis estouros de jornadas ocasionados por variáveis não controladas, como: congestionamento, quebra de veículos, filas de 
atendimento em cliente etc., porém em comparação com o cenário anterior, demonstra-se estabilidade.

Para uma melhor análise do projeto, sugere-se que para um futuro trabalho, seja contemplado um modelo completo do fluxo interno, levando em consideração o processo do carregamento noturno e todas as demais atividades desenvolvidas no pátio.

Implementação deste projeto na empresa BETA, trouxe ganhos operacionais com rentabilidade financeira, o centro de distribuição foi vencedor do programa de excelência logística por atingir performance operacional e financeira, que possibilitou a oportunidade da gestão realizar visita internacional para absorver novas técnicas. O projeto pode ser implementado nos demais Centro de Distribuição da empresa BETA. 


\section{Referências bibliográficas}

ANDRADE, E.L. DE. Introdução a Pesquisa Operacional: métodos e modelos para análise de decisão. 3. ed. Rio de Janeiro: LTC, 2004.

ANDREW M. and BRYNJOLFSSON, E. Investing the IT that Makes a Competitive difference, Harvard Business Review, July-August 2008.

AQUILIANO, N.J.; CHASE, R.B. and JACOBS, F.R. Administração da Produção para a Vantagem Competitiva. 10. ed. Porto Alegre, RS. Bookman, 2004.

ASSAD, A.A. Modeling and implementation issues in vehicle routing. In: Vehicle Routing: Methods an studies, B.L. Golden, A.A. Assad (eds), North Holland, Amsterdam, p.7-46, 1988.

BALLOU, R. Gerenciamento da cadeia de suprimentos/logística empresarial. P. Alegre: Bookman, 2010.

BANKS, J. and CARSON, J.S. Discrete-Event System Simulation. Englewood Cliffs, NJ, Prentice Hall, 1984.

BODIN, L.D.; GOLDEN, B.; ASSAD, A. and BALL, M. Routing and scheduling of vehicles and crews: The states of the art. Computers and Operations Research, vol.10, n.1., 1983.

BRANSKI, R.M. O papel da tecnologia da informação no processo logístico: estudo de casos com operadores logístico. Tese (Doutorado) Escola Politécnica da Universidade de São Paulo. Engenharia de Produção, 2008.

BREAKERS, K.; RAMAEKERS, K. and NIEUWENHUYSE, I.V. The vehicle routing problem: state of the art classification and review. Computers \& Industrial Engineering, 2016.

CHWIF, L. Redução de Modelos de Simulação de Eventos Discretos na sua Concepção: Uma Abordagem Causal. Escola Politécnica da Universidade de São Paulo, 1999.

Campebell, A. M., \& Wilson, J. H. (2014). Forty years of periodic vehicle routing. Networks, 63(1), 2-15.

CUNHA, C.B. Aspectos Práticos da Aplicação de Modelos de Roteirização de veículos a Problemas Reais. São Paulo: EPUSP Departamento de Engenharia de Transportes, 2001.

VAINNA, D.C. e R.C. GOMES, R.C. Um Algoritmo Evolutivo para o problema de Roteamento em Arcos Capacitados, NPDI, 2006. 
DROR, M. and TRUDEAU, P. Split Delivery Routing. Naval Research Logistics, v. 37, p. 383-402, 1990.

EKISIOGLU, B.; VURAL, A.V. and REISMAN, A. The vehicle routing problem: A taxanomic review. Computers \& industrial engineering, 57(4), 1472-1483, 2009.

FIORONI, M.M. Simulação em ciclo fechado de malhas ferroviárias e suas aplicações no brasil: avaliação de alternativas para o direcionamento de composições. Tese de Doutorado. Escola Politécnica da Universidade de São Paulo. São Paulo, 2007.

GOEL, A. Vehicle scheduling and routing with drivers working hours. Transportation science, 43(1), 17-26, 2009.

GORDON, G. System Simulation. Englewood Cliffs, Prentice-Hall -1969.

HONG, L. Na improved LNS algorithm for real-time vehicle routing problem with time Windows. Computer \& Operations Research, 39(2), 151-163, 2012. http://dx.doi.org/10.1016/j.cor.2011.03.006.

TAVARES, J.A. Uma Abordagem Evolucionária ao Problema do Encaminhamento de veículos, UC, 2003.

KOK, A.L.; MEYER, C.M.; KOPFER, H. and SCHUTTEN, J.M.J. A Dynamic programming heuristic for the vehicle routing problem with time windows and european community social legislation. Transportation Science, 44(4), 442454, 2010.

LAUDON, K.C. and LAUDON, J.P. Management Information Systems: managing the digital firm. New Jersey: Prentice Hall, 8ª edição, 2004.

LAURINDO, F.J.B. e MESQUITA, M.A. Material requerimentos planning: 25 anos de história - Uma revisão do passado e prospecção do futuro. São Carlos: Gestão \& Produção, v. 7, no 3, dezembro de 2000. $<$ http://www.scielo.br/scielo.php?pid=S0104-530X2000000300009\&script =sci_arttext $>$.

MARQUES, V. Utilizando o TMS para uma gestão eficaz de transporte. Artigo CEL - Coppead. Universidade Federal do Rio de Janeiro, 2002, Disponível em:http://www.ilos.com.br/web/index.php?option=com_content\&tarsk=view\&id $=1100$ \&itermid=74\&lang=br.

MONKS, J. Administração da produção. (Tradução: Lauro Santos Blandy; revisão técnica: Petrônio Garcia Martins). São Paulo: McGraw-Hill, 1987.

NOVAES, A.G. (1989) Logística e gerenciamento da cadeia de distribuição. $2^{\mathrm{a}}$. Ed. Rio de Janeiro: Campos, 2004.

OHNO, T. Sistema Toyota de Produção: Além da Produção em Escala. Porto Alegre: Editora Bookman, 1997. 
OHNO, T. (1988) O Sistema Toyota de Produção: além da produção em larga escala. Porto Alegre: Bookman, 1997 (edição norte-americana de 1988 e primeira edição japonesa de 1978).

SILVA JÚNIOR, O.S. da. Algoritmo para problemas de Roteirização Estática e Dinâmica de Veículos com Janela de Tempo. Tese (Doutorado) Pontifícia Universidade Católica do Rio de Janeiro, Rio de Janeiro: PUC, Departamento de Engenharia Industrial, 2013.

PAPADOPOULOS, H.; HEAVEY, C. and BROWNE, J. Queuing theory in manufacturing systems analysis and design. London: Chapman \& Hall, 1993.

PEGDEN, C D.; SHANNON, R.E. and SADOWSKI, R.P. Introduction to Simulation using, Siman, 2 ed,, 1995

PELIZARO, C. Avaliação de desempenho do algoritmo de um programa comercial para roteirização de veículos. Dissertação (Mestrado em Engenharia Civil) Universidade de São Paulo, 2000.

PRADO, D. Teoria das filas e da simulação: série pesquisa operacional. v. 2. 5. ed. Nova Lima: Falcolni, 2014. 152 p..

PRADO, D.S. Usando o Arena em simulação. Belo Horizonte: INDG Tecnologia e Serviços Ltda., 2010.

PIDD, M. Computer simulation in management science. Chichester: John Wiley \& Sons, 1998.

BELFIORE, P.P. e FÁVERO, L.P. Problema de roteirização de veículos com entregas fracionadas: revisão da literatura, SIMPEP-Baurau, SP, 2006.

PILAC, V.; GENDREAU, M.; GUERET, C. and MEDAGLIA, A.L. A review of dynamic vehicle routing problems. European Journal of Operational Research, 225(1), 1-11, 2013.

POTVIN, J.Y. and ROUSSEAU, J.M. A parallel route building algorithm for the vehicle routing and scheduling problem with time windows. European Journal of Operational Research, v. 66, n. 3, p. 331-340, 1993.

PRODANOV, C.C. Manual de metodologia científica. 3.ed. Novo Hamburgo, RS: Feevale, 2006.

RANCOURT, M.-E.; CORDEAU, J.-F. and LAPORTE, G. Long-haul vehicle routing and scheduling with working hour rules. Transportation science, 47(1), 81-107, 2013.

REPOUSSIS, P.P.; TARANTILIS, C.D.; BRAYSYS, O. and LOANNOU, G. A hybrid evolution strategy for the open vehicle routing problem. Computer \& Operations Research, 37(3), 443-455, 2010. 
SOLOMON, M.M. On the worst-case performance of some heuristics for the vehicle routing and scheduling with time windows constraints. Networks, v. 16, n. 2, p. 161-174, 1986.

SOLOMON, M.M. Algorithms for the Vehicle Routing and Scheduling Problems with Time Windows Constraints. Operations Research, v. 35, n. 2, p. 254-265, 1987.

SHOOK, J.; ROTHER, M. Aprendendo a Enxergar - Mapeando o Fluxo de Valor para Agregar Valor e Eliminar o Desperdício. São Paulo: Lean Institute Brasil, 1999.

SILVA, C.R.O. Metodologia do trabalho cientifico. Fortaleza: Centro Federal de Educação Tecnológica do Ceara, 2004.

SILVA, R.C.O. DA. Avaliação da Implantação de softwares de roteirização de veículos. Dissertação (Mestrado em Engenharia Industrial) Pontifícia Universidade Católica do Rio de Janeiro, Departamento de Engenharia Industrial, 2007.

THIOLLENT, M.A. Metodologia da pesquisa-ação. 8. Ed. São Paulo: Cortez, 1998.

TASAN, A.S. and GEN, M. A genetic algorithm based approach to vehicle routing problem with simultaneous pick-up and deliveries. Computer \& Industrial Engineering, 62(3), 755-761, 2012.

WOMACK, J.P.; JONES, D.T. A Mentalidade Enxuta nas Empresas: Elimine o Desperdício e Crie Riqueza. Rio de Janeiro: Editora Campus, 1998.

PADOVAN, A.G.; OLIVEIRA, P.A. DE; RODRIGUES, S.A. e CERVI, R.G.. Aplicação da pesquisa operacional para análise do atendimento em agência da previdência social. Tekhne e Logos, Botucatu, SP, v. 7, n. 3, Dezembro 2016.

GOLDWASSER, R.S.; LOBO, M.S.C.; ARRUDA, E.F.; ÂNGELO, S.A.; LAPA E SILVA, J.R.; SALLES, A.A. e DAVID, C.M. Dificuldades de acesso e estimativas de leitos públicos para unidades de terapia intensiva no estado do Rio de Janeiro. Rev. Saúde Publica, 2016

ROCHA, L.G. Utilização da teoria das filas para estudo de fluxo de processos de financiamentos habitacionais feitos através de correspondentes bancários. SADSJ - South American Development Society Journal, vol.1, nº. 2, ano 2015.

SANTOS, M. DOS. Redimensionamento da linha de produção de uma fábrica de sacos de lixo empregando simulação de eventos discretos. Universidade Regional do Cariri - URCA. Caderno de cultura e ciência, Ano x, v.15, n.1, Out, 2016.

SAKARUDA, N. e MIYAKE, D.I. Aplicação de simuladores de eventos discretos no processo de modelagem de sistemas de operações de serviços. ENEGEP, Gestão de Produção, São Carlos, v.16, n.1, jan - mar. 2009. 
CACERES-CRUZ, J.; ARIAS, P.; GUIMARANS, D.; RIERA, D. and JUAN, A.R. Vehicles Routing Problem: survey. ACM Computing Surveys, 2014.

PENNA, P.H.V. Um algoritmo unificado para uma classe de problemas de roteamento de veículos com frota heterogênea. Universidade Federal Fluminense, 149ps. Tese de Doutorado em Computação, Brasil, 2012.

SUBRAMANIAN, A.H. Exact and Hybrid Approaches for Vehicle Routing problems. Universidade Federal Fluminense, Thesis Doctor, Brasil, 2012. 


\section{Anexo A \\ Importância da jornada de trabalho no contexto brasileiro}

Conforme mencionando no capitulo 1. Introdução, a Distribuição Física, na região Urbana, é um dos grandes desafios a ser enfrentado devido ao grande número de ativos e pessoas envolvidas e pelas crescentes restrições de circulação impostas pelas cidades que buscam equalizar o fluxo de veículos entre cargas, passageiros e veículos de passeio. Especificamente no Brasil, existe a lei $\mathrm{N}^{\circ}$ 12.619 que desde o dia 30 de Abril de 2012, obriga que seja cumprido o tempo de jornada de trabalho do motorista, sendo:

- $\quad$ Art. 235-C. A jornada diária de trabalho do motorista profissional será a estabelecida na Constituição Federal ou mediante instrumentos de acordos ou convenção coletiva de trabalho.

- $\quad \S 1^{\circ}$ Admite-se a prorrogação da jornada de trabalho por até 2 (duas) horas extraordinárias.

- $\quad \S 2^{\circ}$ Será considerado como trabalho efetivo o tempo que o motorista estiver à disposição do empregador, excluídos os intervalos para refeição, repouso, espera e descanso.

- $\quad \S 3^{\circ}$ Será assegurado ao motorista profissional intervalo mínimo de 1 (uma) hora para refeição, além de intervalo de repouso diário de 11 (onze) horas a cada 24 (vinte e quatro) horas e descanso semanal de 35 (trinta e cinco) horas.

O não cumprimento ou a falta de registro que justifique a ocorrência, pode vir a gerar penalidades financeiras ao empregador. A legislação diz que quando o intervalo para repouso e alimentação não for concedido pelo empregador, este ficará obrigado a remunerar o período correspondente com acréscimo de, no mínimo, 50\% sobre o valor da remuneração da hora normal de trabalho. Em procedimento de fiscalização do Ministério do Trabalho a empresa também ficará sujeita a multa de $\mathrm{R} \$ 40,25$ a $\mathrm{R} \$$ 4.025,33, dobrada na reincidência, oposição ou desacato por infração ao artigo 71 da CLT, o qual dispõe que em qualquer trabalho contínuo, cuja duração exceda a seis horas, é obrigatória a concessão de intervalo para refeição e repouso de no mínimo uma hora. 
A redução do intervalo será indevida quando o empregador, ainda que tenha previsão em cláusula convencional, não atender às exigências das normas de segurança e saúde no trabalho, das exigências concernentes aos refeitórios ou ainda, quando submeter os empregados a regimes de horas extraordinárias.

Não havendo a concessão do intervalo de, no mínimo, uma hora ou se comprovada a redução indevida por estar em desacordo com a previsão legal, o empregador estará sujeito ao pagamento do intervalo nos termos da Orientação Jurisprudencial 307 da SBDI-1 do TST.

Da mesma forma, se o intervalo Inter jornada não for obedecido, garante o recebimento de horas extras consoante entendimento do TST, consubstanciado na Súmula 110 que dispõe:

"Súmula 110 - No regime de revezamento, as horas trabalhadas em seguida ao repouso semanal de 24 (vinte e quatro) horas, com prejuízo do intervalo mínimo de 11 (onze) horas consecutivas para descanso entre jornadas, devem ser remuneradas como extraordinárias, inclusive com o respectivo adicional." 